\title{
Development of natural rubber foam with water as a blowing agent via microwave and convection heating methods
}

\author{
Nur Syuhada Ahmad Zauzi,2(1), Zulkifli Mohamad Ariff ${ }^{*}{ }^{(\mathbb{1}}$, Raa Khimi Shuib ${ }^{10}$ \\ ${ }^{1}$ School of Materials and Mineral Resources Engineering, University Sains Malaysia, Nibong Tebal, Penang, Malaysia \\ ${ }^{2}$ Faculty of Engineering, Universiti Malaysia Sarawak, Kota Samarahan, Sarawak, Malaysia
}

Received 25 August 2021; accepted in revised form 24 October 2021

\begin{abstract}
This study used water as the physical blowing agent as well as microwave heating (MH) and convection heating $(\mathrm{CH})$ to simultaneously foam and cure natural rubber foam (NRF). Various processing methods and parameters, such as single heating and sequential heating using a mix of $\mathrm{CH}$ and $\mathrm{MH}$; were investigated. The correlation between these processing methods as well as different water loadings was then evaluated and compared in terms of physical appearance, density, and morphology. The NRF samples produced using sequential MH and $\mathrm{CH}$ (SMC) heating exhibited better shape and structure than samples produced using single heating of either $\mathrm{CH}$ or $\mathrm{MH}$ only as well as sequential $\mathrm{CH}$ and $\mathrm{MH}$ (SCM) heating at all water loadings. NRF samples with water loadings of 1.5 and $2.0 \mathrm{phr}$ had a density of less than $0.1 \mathrm{~g} / \mathrm{cm}^{3}$. The potential heating mechanism of all the heating methods explored in this study was proposed and discussed to further understand the microwave heating process. The findings of this study proved that water could be utilized as a physical blowing agent in the production of NRF products with microwave-assisted foaming.
\end{abstract}

Keywords: rubber microwave, water, blowing agent, rubber, natural rubber foam

\section{Introduction}

Rubber foam, or cellular foam, contains voids surrounded by a continuous phase of rubber. As such, it is lightweight and possesses comparable mechanical properties. This makes it a popular choice in many fields and applicable for use as a thermal, electrical, and acoustic insulator as well as packaging, flooring, and upholstery foam $[1,2]$. The manufacturing technology as well as the type of blowing agent used during rubber foam production, are important as they affect the structure and properties of the final foam [3-5]. Two-stage heat transfer, a relatively lengthy process, is typically used to manufacture rubber foam from dry rubber. However, microwave processing technology has been successfully applied in various industries, such as the chemical, rubber production, food processing, and vacuum drying industries $[6,7]$. Of the many advantages of microwave heating, rapid and uniform heating provide opportunities to produce new materials $[3,6,8,9]$. As such, the use of microwave heating for material foaming has gained popularity among researchers as a viable heating method. Furthermore, microwave-assisted foaming is an inexpensive and quick method of producing cellulose-based foams with an opencell structure [7]. Prociak et al. [9] evaluated the efficacy of using microwave irradiation to heat and foam thermoplastic polyurethane (TPU) with carbon black as a filler. Their results indicated that microwave irradiation could be utilized to prepare TPU foam composites in-situ using a chemical blowing agent. However, the heating efficacy of microwave 
technology is influenced by parameters and conditions, such as the mass and type of polyurethane as well as the type and position of the mould within the microwave processing system [9].

Chemically active blowing agents, such as azodicarbonamide (ADC) and dinitrosopentamethylenetetramine (DNPT); are frequently used in the rubber foam industry because they are less harmful than chlorofluorocarbon-based foaming agents. However, these blowing agents are not only expensive, but the by-products of their thermal decomposition can retard or accelerate the vulcanization process. Therefore, there is an urgent need to identify more environmentally friendly foaming methods that do not use chemically reactive foaming agents $[4,10]$. Unlike other blowing agents, water is a distinct physical blowing agent due to its low volatility, low cost, low environmental impact, and very low solubility [11]. Furthermore, it is readily available and the equipment needed for compounding and processing is standard and does not require specialized handling. Water has been utilized in the production of ethylene-propylene-diene monomer (EPDM) foam via injection moulding [12]. The minimum densities of foam that had been produced using a water-based blowing agent and ADC, a commercial blowing agent, were 0.5 and $0.35 \mathrm{~g} / \mathrm{cm}^{3}$, respectively. Sahnoune [11] investigated using water to foam polypropylene (PP), and thermoplastic elastomer (TPE) blends using injection moulding. The study found that the resultant foam possessed larger cell sizes and more severe cell ruptures as the water content increased [11]. Therefore, water content affects cell size and cell structure.

To date, only a few studies have examined the use of water as a blowing agent in natural rubber foaming. Therefore, the purpose of this present study was to explore the feasibility of using water and microwave-assisted foaming in the production of natural rubber foam (NRF) products. Various heating methods were investigated at different parameters before the resulting NRF samples were evaluated and compared in terms of physical appearance, density, and morphology. The heating mechanism of two heat sources, microwave and convection, were also compared to better understand the foaming behaviour of the resultant NRF samples.

\section{Methodology}

\subsection{Materials}

Grade L standard Malaysian rubber (SMR-L) was obtained from a local supplier that met the technical standards of the Malaysian Rubber Board. Industrialgrade chemicals from Bayer Co., Ltd were the vulcanization ingredients used to produce the natural rubber (NR) compounds (Table 1).

\subsection{Compound preparation}

Four NR compounds were prepared by adding the ingredients in the order shown in Table 1 into a laboratory rubber mixing two-roll mill (TAIDA ${ }^{\circledR}$ Model XK-160) for 20 minutes. Water was added to the tetramethyl thiuram disulfide (TMTD) and stirred for 5 minutes so the TMTD would act as a water carrier. This mixture was left to stand for 15 minutes before it was added to the NR compounds to avoid adding water in its liquid state directly to the tworoll mill, which would result in water loss during mixing. The NR compounds were then stored in a freezer for at least 24 hours prior to foaming.

\subsection{Sample preparation and processing}

Figure 1 shows the four NR samples prior to foaming. The numbers on each sample; $0.5,1.0,1.5$, and 2.0, indicate the water loading of each sample. As seen in Figure 1a, each sample was cut into a $40 \mathrm{~mm}$ diameter circle measuring $8 \mathrm{~mm}$ in thickness and placed on separate $55 \mathrm{~mm}$ diameter glass petri dishes. Figure $1 \mathrm{~b}$ depicts the arrangement of the samples on the glass turntable of the microwave oven. This arrangement was standardized at every parameter setting to ensure that every sample received uniform heating. Foaming and curing were conducted using

Table 1. The vulcanization ingredients used to produce the NR compounds.

\begin{tabular}{|l|c|}
\hline \multicolumn{1}{|c|}{ Ingredients } & $\begin{array}{c}\text { Parts per hundred rubber } \\
\text { [phr] }\end{array}$ \\
\hline SMR-L & 100.0 \\
\hline Stearic acid & 2.0 \\
\hline Zinc oxide (ZnO) & 4.0 \\
\hline $\begin{array}{l}N \text {-cyclohexyl-2-benzothiazole- } \\
\text { sulfenamide (CBS) }\end{array}$ & 1.0 \\
\hline $\begin{array}{l}\text { Tetramethylthiuram disulfide } \\
\text { (TMTD) }\end{array}$ & 2.5 \\
\hline Distilled water (water) & $0.5 / 1.0 / 1.5 / 2.0$ \\
\hline Sulphur & 1.5 \\
\hline
\end{tabular}



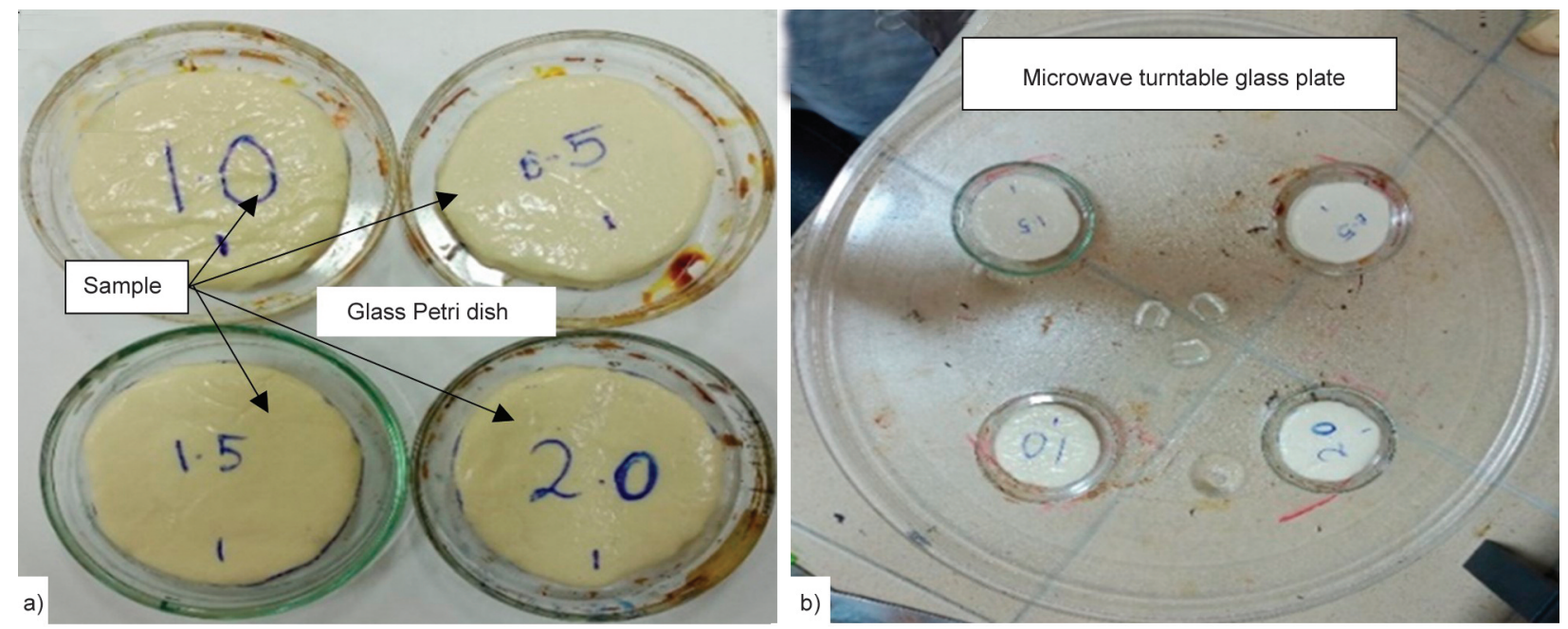

Figure 1. The unfoamed sample (a) in the glass petri dish and (b) arranged on the glass turntable of the microwave oven.

a household microwave oven (Panasonic ${ }^{\circledR}$ Model NN-CD565B) with a 271 capacity, $2.45 \mathrm{GHz}$ operating frequency, and $1000 \mathrm{~W}$ power rating. As seen in Table 2, two processing methods were employed: single heating and sequential heating. During single heating, only microwave heating $(\mathrm{MH})$ or convection heating $(\mathrm{CH})$ was applied at different parameter settings. However, during sequential heating, both $\mathrm{MH}$ and $\mathrm{CH}$ were utilized in a pre-determined sequence.

\subsection{Natural rubber foam characteristics}

\subsubsection{Curing characteristics}

The curing characteristics of the water loaded NRF samples were obtained according to ASTM D 224 specifications. Approximately 4 grams of each NRF sample was placed in a moving die rheometer (Monsanto ${ }^{\circledR}$ Model MDR2000) at $150^{\circ} \mathrm{C}$ for 30 minutes. The scorch time; the time required for a two-unit increase from minimum torque $\left(t_{\mathrm{s} 2}\right) ; 90 \%$ of cure time $\left(t_{90}\right)$ as well as the maximum $\left(M_{\mathrm{H}}\right)$ and minimum

Table 2. The processing methods and parameters used to produce the natural rubber foam (NRF) samples via microwave and convection heating.

\begin{tabular}{|c|c|c|c|c|c|}
\hline \multirow[b]{2}{*}{ Processing method } & \multirow[b]{2}{*}{ Heating technique } & \multirow[b]{2}{*}{ Sample designation } & \multicolumn{3}{|c|}{ Parameters } \\
\hline & & & $\begin{array}{c}\text { Power } \\
{[W]}\end{array}$ & $\begin{array}{c}\text { Temperature } \\
{\left[{ }^{\circ} \mathrm{C}\right]}\end{array}$ & $\begin{array}{l}\text { Time } \\
\text { [min] }\end{array}$ \\
\hline \multirow{4}{*}{ Single heating } & \multirow{2}{*}{$\begin{array}{c}\text { Microwave heating } \\
(\mathrm{MH})\end{array}$} & MH1 (MH1000_15) & 1000 & & 15 \\
\hline & & MH2 (MH600_18) & 600 & & 18 \\
\hline & \multirow{2}{*}{$\begin{array}{l}\text { Convection heating } \\
(\mathrm{CH})\end{array}$} & CH1 (CH150_15) & & 150 & 15 \\
\hline & & CH2 (CH170_8) & & 170 & 8 \\
\hline \multirow{16}{*}{ Sequential heating } & \multirow{8}{*}{$\begin{array}{c}\text { Sequential: } \\
\text { first heating }\left(1^{\text {st }}\right) \text { : } \\
\text { microwave, } \\
\text { followed by second heating }\left(2^{\text {nd }}\right) \text { : } \\
\text { convection }(\mathrm{SMC})\end{array}$} & \multirow{2}{*}{$\begin{array}{c}\text { SMC1A } \\
\left(\mathrm{MH} 1000 \_10: \mathrm{CH} 150 \_10\right)\end{array}$} & $1^{\text {st: }} 1000$ & & 10 \\
\hline & & & & $2^{\text {nd. }}: 150$ & 10 \\
\hline & & \multirow{2}{*}{$\begin{array}{c}\text { SMC1B } \\
\left(\mathrm{MH} 1000 \_12: \mathrm{CH} 150 \_8\right.\end{array}$} & $1^{\text {st: }} 1000$ & & 12 \\
\hline & & & & $2^{\text {nd. }}: 150$ & 8 \\
\hline & & \multirow{2}{*}{ 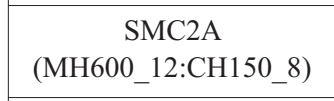 } & $1^{\text {st }}: 600$ & & 12 \\
\hline & & & & $2^{\text {nd. }}: 150$ & 8 \\
\hline & & \multirow{2}{*}{$\begin{array}{c}\text { SMC2B } \\
\text { (MH600_14:CH150_6 }\end{array}$} & $1^{\text {st }}: 600$ & & 14 \\
\hline & & & & $2^{\text {nd. }}: 150$ & 6 \\
\hline & \multirow{8}{*}{$\begin{array}{c}\text { Sequential: } \\
\text { first heating }\left(1^{\mathrm{st}}\right) \text { : } \\
\text { convection, } \\
\text { followed by second heating }\left(2^{\text {nd }}\right) \text { : } \\
\text { microwave }(\mathrm{SCM})\end{array}$} & \multirow{2}{*}{$\begin{array}{c}\text { SCM1 } \\
\left(\mathrm{CH}: 150 \_10: \mathrm{MH} 600 \_5\right)\end{array}$} & & $1^{\text {st: }} 150$ & 10 \\
\hline & & & $2^{\text {nd: }}: 600$ & & 5 \\
\hline & & \multirow{2}{*}{$\begin{array}{c}\text { SCM2 } \\
\left(\mathrm{CH}: 150 \_5: \mathrm{MH} 600 \_8\right)\end{array}$} & & $1^{\text {st: }} 150$ & 5 \\
\hline & & & $2^{\text {nd: }}: 600$ & & 8 \\
\hline & & \multirow{2}{*}{$\begin{array}{c}\text { SCM3 } \\
\left(\mathrm{CH}: 150 \_8: M H 600 \_4\right)\end{array}$} & & $1^{\text {st: }} 150$ & 8 \\
\hline & & & $2^{\text {nd: }} 600$ & & 4 \\
\hline & & \multirow{2}{*}{$\begin{array}{c}\text { SCM4 } \\
\text { (CH:150_8:MH1000_6) }\end{array}$} & & $1^{\text {st: }} 150$ & 8 \\
\hline & & & $2^{\text {nd: }} 600$ & & 6 \\
\hline
\end{tabular}


torque $\left(M_{\mathrm{L}}\right)$ on the cured trace of the NRF samples were measured and analyzed. The difference between the maximum and minimum torque $(\Delta S)$ indicates the crosslink density of the rubber. Equation (1) was used to determine the cure rate index (CRI) $[13,14]$ :

Cure rate index $=\frac{100}{t_{60}-t_{\mathrm{s} 2}}$

\subsubsection{Physical appearance and morphology}

A digital camera was used to photograph the NRF samples. The salient physical characteristics of the NRF samples, such as skin surface, shape, cell distribution, and cross-section parallel to foam rise direction, were compared. A scanning electron microscope (SEM) (Hitachi ${ }^{\circledR}$ Model TM3000 Tabletop SEM) was used to further analyze the cell structure of each NRF sample. A mini sputter coater (Quorum ${ }^{\circledR}$ Model SC7620) was used to coat the surface of each NRF sample with a thin layer of palladium. Two cross-sectional surfaces that were parallel and perpendicular to the direction of the foam rise were observed and compared. SEM images were captured at $50 \times$ magnifications. In order to examine the cell size and cell size distribution, a few locations of each sample that were parallel to the foam rise direction were captured and measured using an image processing programme (ImageJ). For statistical validity, at least 100 cells were measured for average cell size and cell size distribution.

\subsubsection{Crosslink density}

Crosslink density was measured in toluene in accordance with ASTM D471-98 specifications. After the initial weights were recorded using an electronic weighing balance, the skin of each sample was cut into three different shapes. These samples were then immersed in a glass vessel containing toluene for 6 hours at room temperature (approximately $28^{\circ} \mathrm{C}$ ). The samples were subsequently removed from the vessel, wiped thoroughly to remove excess solvent, and reweighed. This second set of weight measurements was denoted as the swollen weight of the samples. The crosslink density ( $\left.v_{\text {cross }}\right)$ was then measured using the Flory-Rehner Equation (2) [15, 16]:

$v_{\text {cross }}\left[\frac{\mathrm{mol}}{\mathrm{cm}^{3}}\right]=\frac{1}{2 M_{\mathrm{c}}}=-\frac{\ln \left(1-v_{r}\right)+v_{r}+\chi v_{\mathrm{r}}^{2}}{2 \rho_{\mathrm{r}} V_{\mathrm{s}}\left(\sqrt[3]{v_{\mathrm{r}}}-\frac{v_{\mathrm{r}}}{2}\right)}$ where $v_{\mathrm{r}}$ is the volume fraction of rubber in the swollen sample, $V_{\mathrm{S}}$ is the molar volume of toluene $\left(106.4 \mathrm{~cm}^{3} / \mathrm{mol}\right), \rho_{\mathrm{r}}$ is the density of rubber $\left(0.93 \mathrm{~g} / \mathrm{cm}^{3}\right), \chi$ is the interaction parameter of the rubber network-solvent $(0.42)$, and $M_{\mathrm{c}}$ is the physical crosslink concentration. Equation (3) was used to determine the $v_{\mathrm{r}}$ :

$$
v_{\mathrm{r}}=\frac{\frac{X_{\mathrm{r}}}{\rho_{\mathrm{r}}}}{\frac{X_{\mathrm{r}}}{\rho_{\mathrm{r}}}+\frac{X_{\mathrm{s}}}{\rho_{\mathrm{s}}}}
$$

where $X_{\mathrm{r}}$ is the mass fraction of rubber $[\mathrm{g}], X_{\mathrm{S}}$ is the mass fraction of toluene $[\mathrm{g}]$, and $\rho_{\mathrm{s}}$ is the density of toluene $\left(0.87 \mathrm{~g} / \mathrm{cm}^{3}\right)$. Here, $X_{\mathrm{s}}$ and $X_{\mathrm{r}}$ can be calculated using Equations (4) and (5), respectively [5]:

$X_{\mathrm{s}}=\frac{\text { Weight of swollen sample }- \text { Initial weight }}{\text { Weight of swollen sample }}$

$X_{\mathrm{r}}=1-X_{\mathrm{s}}$

\subsubsection{Density and relative foam density}

As seen in Equation (6), the density of the NRF samples was measured by dividing the mass by the volume of the samples. Shaver blades were used to completely remove the skin and cut the samples into $20 \mathrm{~mm} \times 20 \mathrm{~mm} \times 20 \mathrm{~mm}$ pieces. Irregularities; such as big pores; were also removed from the bulk foam samples. Density was then determined using the average value of three samples. Equation (7) was used to determine the relative foam density [16]:

Density, $\rho=\frac{m}{V}$

where $m$ - mass [g], $V$ - volume $\left[\mathrm{cm}^{3}\right]$

Relative density $=\frac{\rho_{\mathrm{f}}}{\rho_{\mathrm{s}}}$

where $\rho_{f}-$ foam density, $\rho_{s}-$ solid density.

\subsubsection{Expansion ratio}

Equation (8) was used to measure foam expansion ratio $[16,17]$ :

Expansion ratio $=\frac{H_{\mathrm{f}}-H_{0}}{H_{0}}$

where $H_{\mathrm{f}}$ - height after foaming, $H_{0}-$ initial height. 


\subsubsection{Cell density}

Equation (9) was used to calculate cell density $\left(d_{\text {cell }}\right)$ [18]:

$d_{\mathrm{cell}}=\frac{3}{4 \pi r^{3}}\left(1-\frac{\rho}{\rho_{\mathrm{s}}}\right)$

where $\rho$ is the foam density, $\rho_{\mathrm{s}}$ is the solid density (NR $0.93 \mathrm{~g} / \mathrm{cm}^{3}$ ), and $r$ is the average cell radius [cm].

\section{Results and discussion}

\subsection{Effect of processing method on the physical characteristics of natural rubber foam}

\subsubsection{Single heating method}

The natural rubber (NR) compounds, with water loadings of $0.5,1.0,1.5$, and 2.0, were each subjected to four distinct heating methods at two different parameter settings. The resulting natural rubber foam (NRF) samples were then analyzed and compared. Single heating using either microwave heating $(\mathrm{MH})$ or convection heating $(\mathrm{CH})$ was performed to determine the correlation between the foaming and curing processes of each single heating method. Figure 2 displays samples exposed to $\mathrm{MH}$ at $600 \mathrm{~W}$ at different exposure times. As seen in Figure 2a, the samples initially foamed well and formed uncured, tacky, and smooth skins with no blisters. However, blisters formed on the surface as the processing time increased to 15 minutes (Figure 2b). Therefore, the samples should not be exposed to MH for more than 12 and 10 minutes at 600 and $1000 \mathrm{~W}$, respectively. Figure 3 provides top and cross-sectional views perpendicular to the foam rise direction of NRF samples produced via two distinct single heating methods at different water loadings. Prominent differences in the skin surface, foam shape, and cell distribution

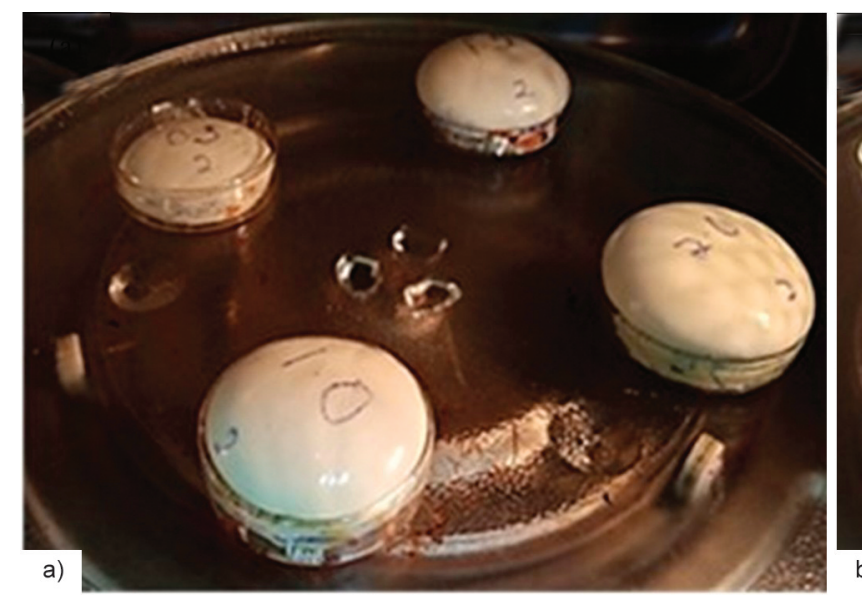

Figure 2. The samples during foaming and curing via MH: (a) at 12 minutes at $600 \mathrm{~W}$ and (b) at 15 minutes at $600 \mathrm{~W}$.

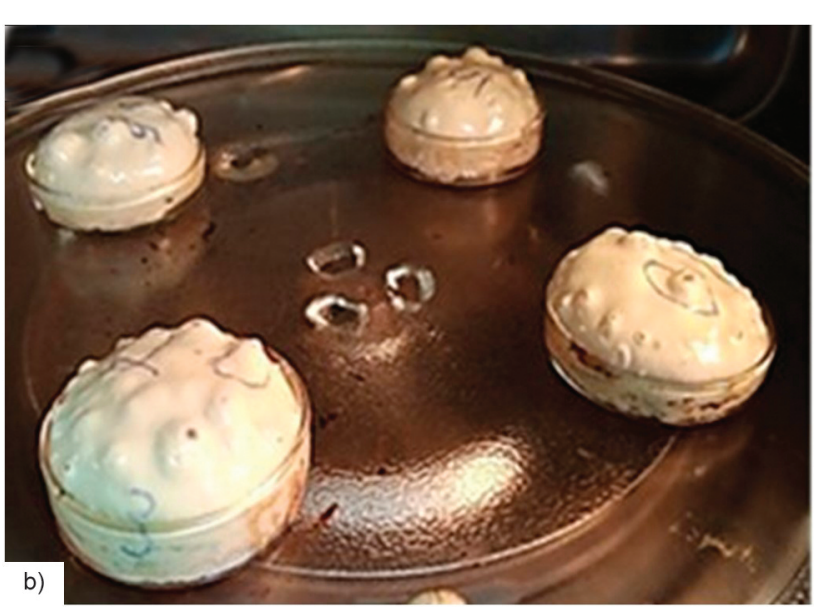

were noted. As seen in Figures $3 a$ and $3 b$, samples subjected to $\mathrm{MH}$ at $1000 \mathrm{~W}$ for 15 minutes (MH1) and $600 \mathrm{~W}$ for 18 minutes (MH2), respectively, produced NRF samples with a flat surface and uneven skin as several blisters breached the skin (indicated by black circles). Except cells near the skin surface, the samples also exhibited a controlled foam cell structure. Therefore, the exposure time was reduced in an attempt to prevent the formation of blisters. However, the foam collapsed as the outer and inner surfaces did not fully cure even after the foam was allowed to stand for a few seconds at room temperature. Conversely, $\mathrm{CH}$ at $150^{\circ} \mathrm{C}$ for 15 minutes (CH1) produced convex-shaped NRF samples with relatively smooth and blister-free skin. However, as seen in Figure 3c, this resulted in uncontrollable foam cell structures at all water loadings. $\mathrm{CH}$ at $170^{\circ} \mathrm{C}$ for 8 minutes $(\mathrm{CH} 2)$ was found to be too hot and too short for successful foaming as it did not produce fruitful NRF samples. The surface of the samples absorbed most of the heat, effectively curing the skin before the heat could be transferred to the inner part of the samples (Figure 3d). Although samples that had been subjected to $\mathrm{CH} 2$ were initially well blown, they collapsed once they were removed from the oven and allowed to stand at room temperature. This could be attributed to insufficient curing of the inner structure as the heat was concentrated on the outer surface of the foam. Based on this observation, it was deduced that an increase in processing time and temperature would not cure the inner parts of the samples. Instead, the skin would become tacky as the rubber compound degraded due to a reversion phenomenon that commonly occurs in certain vulcanized rubber formulations when exposed to prolonged excessive heat. 
Cross-sectional cell structures perpendicular to the foam rise direction are presented in Figures $3 \mathrm{a}_{\mathrm{ii}}, 3 \mathrm{~b}_{\mathrm{ii}}$ and $3 c_{\text {ii. }}$. MH1 (Figure $3 a_{\text {ii }}$ ) and MH2 (Figure $3 b_{\text {iii }}$ ) had uniform cell distributions, while $\mathrm{CH} 1$ (Figure $3 \mathrm{c}_{\mathrm{ii}}$ ) had a random cell distribution with a combination of big and small cells. Nevertheless, big cells were also observed adjacent to the surface of the MH samples. This is believed to be due to blisters on the skin. In terms of water loading, both MH1 and MH2 had positive outcomes as the appearance of big cells near

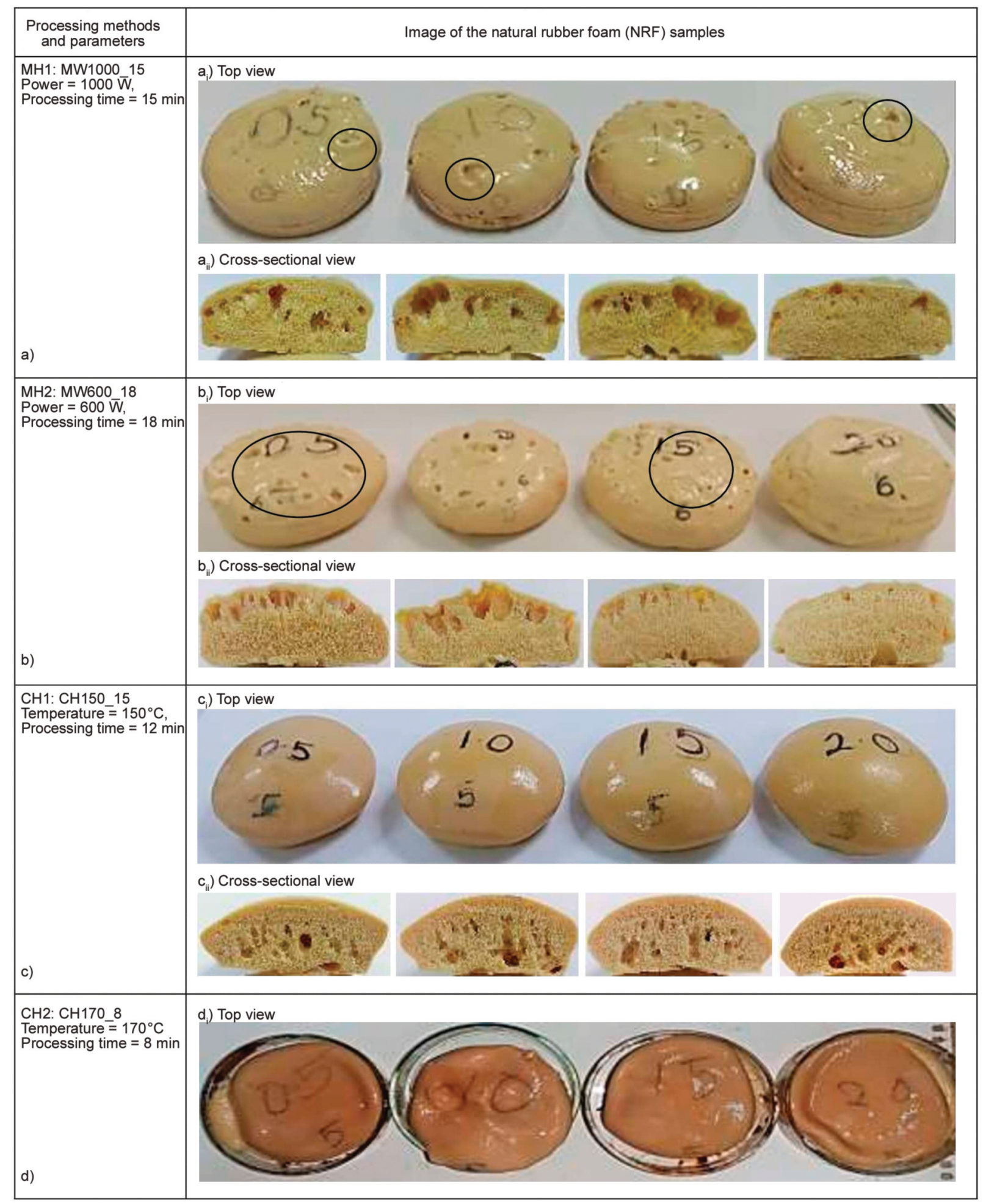

Figure 3. The NRF samples obtained by using only microwave heating or convection heating on NR compounds with different water loadings (i) top views and (ii) cross-sections perpendicular to foam rise direction. (a) MH1: MW1000_15, (b) MH21: MW600_18, (c) CH1: CH150_15, (d) CH2: CH170_8. 
the surface decreased as the water loading increased. However, MH at both $600 \mathrm{~W}$ and $1000 \mathrm{~W}$ still produced blisters on the skin at all water loadings. Therefore, microwave heating alone is insufficient to cure the surface as blisters were apparent and bubbles coalesced on the surface. Apart from that, water and $\mathrm{CH}$ are not recommended for use in open or free-surface rubber foaming. This is because the heat generated during $\mathrm{CH}$ could only heat the outer layer of the samples and could not penetrate and cure the inner parts of the samples before the outer layer was well cured. Therefore, MH was still vital in the water foaming of rubber due to its ability to heat samples from the inside out, producing a uniform and controllable cell structure as opposed to $\mathrm{CH}$. This study went on to introduce $\mathrm{CH}$ in the heating system in an attempt to cure the surface. The results of combining both $\mathrm{MH}$ and $\mathrm{CH}$ techniques is discussed in the following subsection.

\subsubsection{Sequential heating methods}

Sequential heating procedures were designed based on the outcomes of the single heating methods. Figures 4 and 5 depict NRF samples with different water loadings that have been subjected to various sequential heating parameters. A comparatively uniform cell structure and good expansion ratio were observed in NRF samples that had been subjected to sequential microwave-convention heating (SMC). In the SMC method, MH was first used to heat and initiate the foaming and crosslinking processes inside the sample in order to prevent the formation of blisters on the skin. The heating was then switched to $\mathrm{CH}$ in order to heat up and crosslink the outer surface. This technique was able to produce NRF samples with blister-free surfaces, uniform cell structures, and good overall shape, as evidenced by the SMC1A (MH1000_10:CH_10) and SMC2A (MH600_12: CH150_8) samples seen in Figures 4a and, 4c, respectively. The SMC1B (MH1000_12:CH_8) and SMC2B (MH600_14:CH_6) samples had blisters and big cells adjacent to the skin. As such, prolonged heating with MH produced NRF samples with uneven and blistered skin. It indicated that the lower temperature of the microwave cavity delayed crosslinking at the surface as it was not directly heated by microwave radiation. Furthermore, the high rate of internal heating encouraged moisture evaporation. This created a pressure-driven flow of moisture from the inside to the surface, where it accumulated and evaporated to form blisters $[19,20]$.

In the second sequential heating method, sequential convection-microwave (SCM) heating, the samples were first subjected to $\mathrm{CH}$ at $150^{\circ} \mathrm{C}$ followed by $\mathrm{MH}$ at $600 \mathrm{~W}$ and $1000 \mathrm{~W}$ (Figure 5). As the outcomes of the single heating methods discussed in the preceding subsection established that 18 minutes of $\mathrm{CH}$ was excessive, varying exposure times were explored during sequential heating. The SCM1 sample was exposed to $\mathrm{CH}$ for 10 minutes before heating was switched to $\mathrm{MH}$ at $600 \mathrm{~W}$ for 5 minutes. As seen in Figure 5a, the SCM1 sample had similar characteristics as the sample that was subjected to $\mathrm{CH}$ only (Figure 4c). Therefore, the amount of time that the SCM2 sample was subjected to $\mathrm{CH}$ was reduced to 5 minutes followed by $\mathrm{MH}$ at $600 \mathrm{~W}$ for 8 minutes. However, 5 minutes of exposure to $\mathrm{CH}$ was an inadequate amount of time to cure the outer part, and, as a result, blisters appeared on the skin similar to the sample that was subjected to MH only. Furthermore, the colour of the skin and the inner part differed. As seen in Figure $5 b_{i}$, the skin was beige, indicating that it had not cured, while the inner part, seen in Figure $5 b_{i i}$, was yellow, signifying that it had fully cured with no collapsed cells due to the subsequent microwave heating. This indicated that the ideal range of exposure to $\mathrm{CH}$ was between 5 to $10 \mathrm{~min}$ utes. Therefore, 8 minutes of exposure to $\mathrm{CH}$ with several different $\mathrm{MH}$ parameters was decided. When exposure to MH was too short, such as in the case of the SCM3 sample, the resultant NRF had insufficient crosslinks as some of the samples collapsed and a thick skin layer was discovered. As seen in Figure 5c, cells emerged and collapsed in 1.0 and $1.5 \mathrm{phr}$ water NR samples due to localized hotspots as the heated materials had different microwave absorbing properties. This could have been due to the presence of a high amount of water in that area, which would increase its ability to absorb high amounts of electromagnetic waves, leading to the subsequent coalescence of the cell [19]. As seen in Figure $5 \mathrm{~d}$, a similar occurrence was observed in the SCM4 (CH150_8:MH1000_6) samples with water loadings of $0.5,1.0$, and $1.5 \mathrm{phr}$. Cell rupture or coalescence is believed to have occurred as a result of localized heating, whereby certain areas within the NR compound absorbed more heat than others. Meanwhile, the SCM4 sample with a water loading 
of $2.0 \mathrm{phr}$ had good cell distribution. One possible explanation for this is that, at high power, $\mathrm{MH}$ promotes homogeneous temperature distribution and quick thermal response with the aid of higher water loadings.
Apart from cell structure, the shape of the NRF samples also differed between SMC and SCM heating. SCM heating produced convex-shaped samples identical to samples produced using single heating with $\mathrm{CH}$ only, whereas SMC heating produced samples

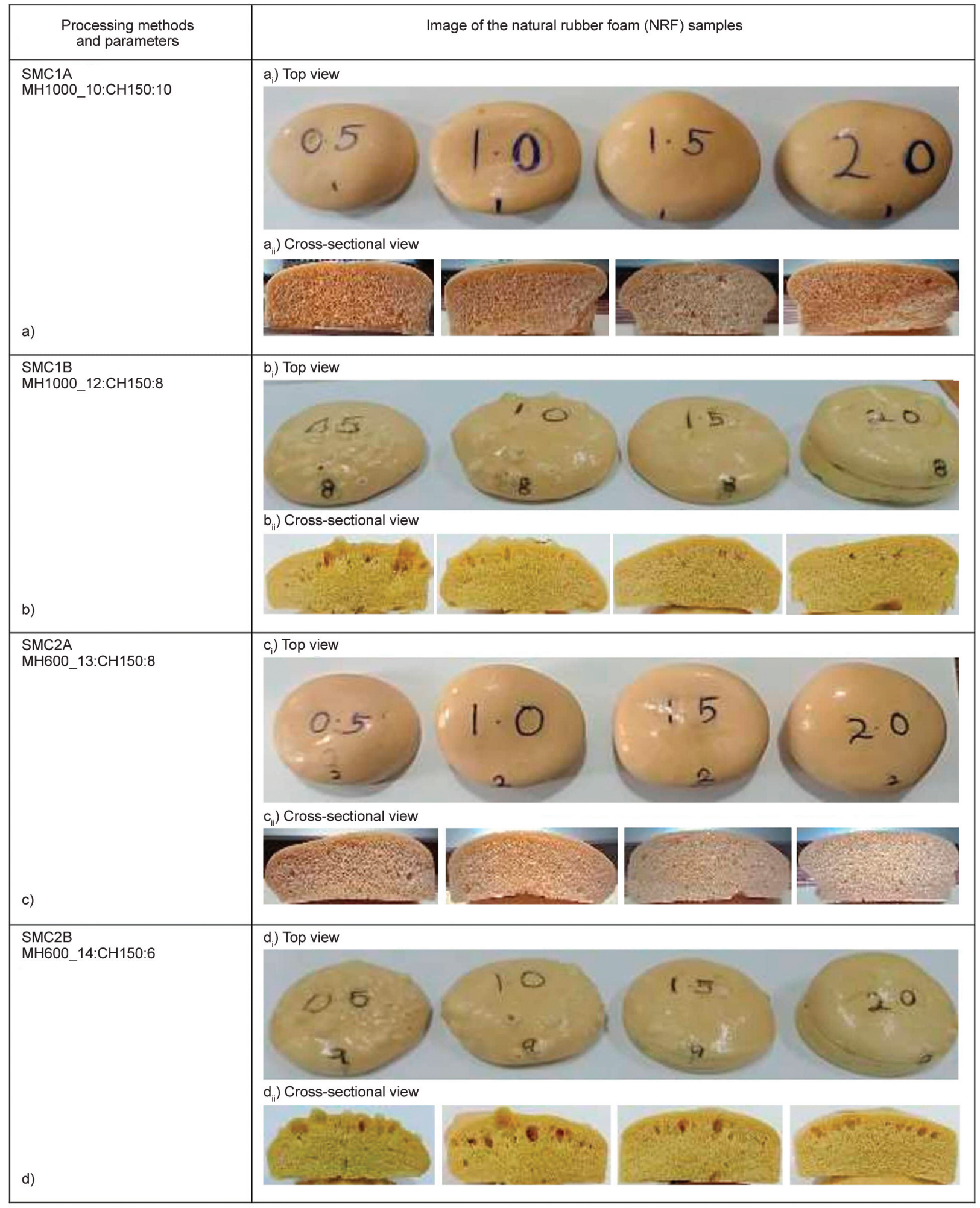

Figure 4. The NRF samples obtained via sequential microwave-convection (SMC) heating of NR compounds with different water loadings (i) top views and (ii) cross-sections perpendicular to foam rise direction. (a) SMC1A, (b) SMC1B, (c) SMC2A, (d) SMC2B. 
that were comparable in shape to samples that had been subjected to heating with MH only. Therefore, the sequential heating outcomes suggest that NRF samples with good cell structure and skin could be produced with the addition of water as a blowing agent. The correlation of the results between $\mathrm{CH}$ and $\mathrm{MH}$ as the first or second heating method provides invaluable insight into the mechanisms of foaming

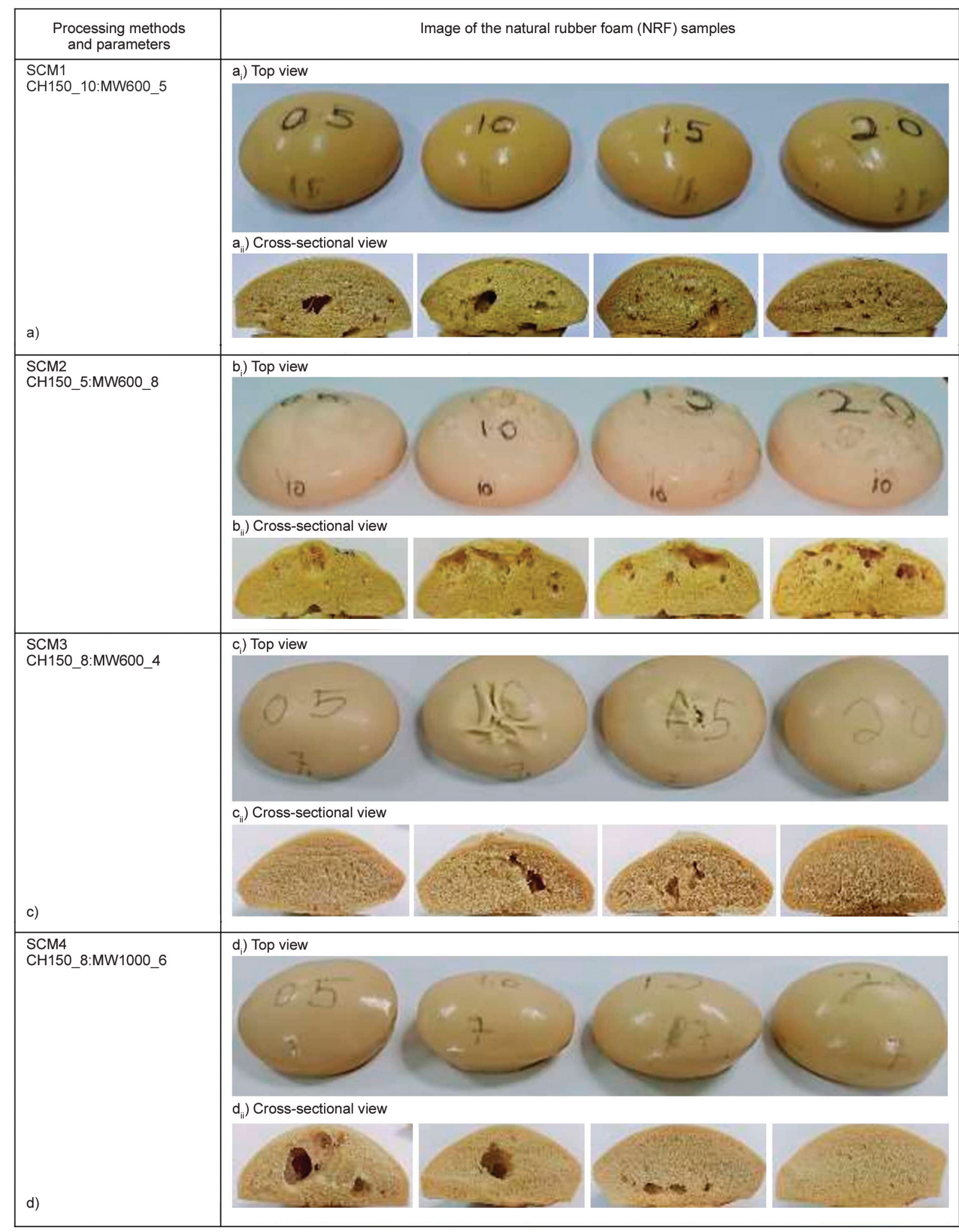

Figure 5. The NRF samples obtained via sequential convection-microwave (SCM) heating of NR compounds with different water loadings (i) top views and (ii) cross-sections perpendicular to foam rise direction. (a) SCM1, (b) SCM2, (c) SCM3, (d) SCM4. 
and curing that occur within NR compounds, which ultimately affects the final NRF product.

\subsection{Crosslink density}

Table 3 lists the effect of different processing methods on the crosslink density of NRF samples with varying water loadings. The results showed that crosslink density decreased as water loading increased regardless of the processing method. Lower crosslink densities indicate that crosslinked rubber permits a large number of solvent molecules to penetrate the rubber chain and molecules. This can be attributed to the presence of water that may affect the viscosity of the NR compound in the presence of heat, which also enhances the chain mobility of the rubber molecules, thereby decreasing the crosslink density of crosslinked NRF samples [22]. Moreover, the curing process might occur either asynchronously or simultaneously with water decomposition or vaporization. As more gas is generated at higher water contents, the gas is more prominent than the solid phase [23]. Additionally, as the decomposition of water is an endothermic process, more heat is absorbed by the water at high water contents, consequently hindering the crosslinking process. A previous study reported that crosslink density decreased as azodicarbonamide (ADC) content increased. It could be attributed to the gas generated by the ADC, thus hindering the sulphur crosslinking reaction in NRF products [24]. In considering the effects of various heating methods, single heating with MH1 produced the lowest crosslink densities for all water loadings in comparison to single heating with $\mathrm{CH} 1$ as well as sequential heating techniques. This is corroborated by other studies that also found that the crosslink densities produced by MH1 and MH2 were extremely low [5, 21, 25]. A low crosslink density implies that the sample is either unvulcanized or only partially vulcanized. It is corroborated by Figures $2 \mathrm{a}$ and $2 \mathrm{~b}$, where the surface of the samples is beige and tacky. Kumnuantip and Sombatsompop [21] reported lower crosslink densities in NR/carbon black/reclaimed rubber blends vulcanizates that had been cured using $\mathrm{MH}$ than $\mathrm{CH}$ [21]. Moreover, the CH1 and SCM3 samples had the highest crosslink densities of all the heating techniques for all water loadings. These findings can be explained by the heat generation distribution and different mechanisms of $\mathrm{MH}$ and $\mathrm{CH}$ as well as the type of crosslinks formed in vulcanizates; -monosulphide or -polysulphide. With regard to the former, in $\mathrm{CH}$, heat is transferred from an external heating source to the surface of a sample and then to the inner parts through thermal conduction or convection. Therefore, the temperature across the thickness of the sample is not uniform, leading to the surface receiving more energy before it is transferred to the inner layers of the sample [26]. However, in SCM heating, the oven chamber is preheated at a set temperature allowing the crosslinking process to promptly initiate on the surface. Conversely, MH generates heat from the inside to the outside of the sample while the oven chamber remains at ambient temperature [21].

During sequential heating, the SCM2 sample had the lowest crosslink density for all water loadings. This could be due to the shorter exposure time of the SCM2 sample; 5 minutes of $\mathrm{CH}$; as opposed to its counterpart, the SCM3 sample, which was exposed to 8 minutes of $\mathrm{CH}$. As such, 5 minutes of $\mathrm{CH}$ was an inadequate amount of time to cure the surface of the NRF sample before switching to MH. As the second heating sequence, $\mathrm{MH}$ was set to 8 minutes. However, it also failed to cure the surface of the sample. Therefore, it is safe to assume that $\mathrm{CH}$ affected the curing of the NRF surface. Furthermore, the surface of the NRF sample could be cured either before or after the termination of MH. Therefore, the results indicate that NR compounds should be subjected to

Table 3. The crosslinking density of NRF samples with varying water loadings after exposure to different heating methods.

\begin{tabular}{|c|c|c|c|c|c|}
\hline \multirow{2}{*}{ Processing method } & \multirow{2}{*}{ Description } & \multicolumn{4}{|c|}{$\begin{array}{c}\text { Crosslinking density } \\
{\left[\cdot 10^{-5} \mathrm{~mol} / \mathrm{cm}^{3}\right]}\end{array}$} \\
\hline & & $0.5 \mathrm{~W}$ & $1.0 \mathrm{~W}$ & $1.5 \mathrm{~W}$ & $2.0 \mathrm{~W}$ \\
\hline \multirow{3}{*}{ Single heating } & MW600_18 & 0.734 & 0.421 & 0.043 & 0.025 \\
\hline & MW1000_15 & 0.894 & 0.803 & 0.445 & 0.317 \\
\hline & CH150_15 & 5.771 & 5.325 & 5.075 & 4.371 \\
\hline \multirow{4}{*}{ Sequential heating } & SMC1A: MW1000_10:CH150_10 & 5.861 & 5.660 & 5.023 & 4.355 \\
\hline & SMC2A: MW600_12:CH150_8 & 5.404 & 5.017 & 4.930 & 4.015 \\
\hline & CH150_5:MW600_8 & 4.537 & 2.154 & 1.943 & 0.958 \\
\hline & CH150_8:MW600_4 & 5.882 & 5.757 & 5.631 & 5.018 \\
\hline
\end{tabular}


a minimum of 8 minutes of $\mathrm{CH}$ to maintain a crosslink density above $4 \cdot 10^{-5} \mathrm{~mol} / \mathrm{cm}^{3}$ for all water loadings.

\subsection{Density and relative density}

Based on Figure 4 and 5, the SMC1A and SMC2A samples were selected for further investigation of the effects of water loading on their physical properties and morphology. These specific samples were selected primarily was to avoid the risk of obtaining misleading results caused by irregular cell structures and non-uniform cell distributions. Furthermore, the effects of water loading were comprehensively compared between four different water loadings in order to gather better insight into the properties of the NRF samples.

Table 4 presents the effects of different processing methods on the density and relative density of NRF samples with varying water loadings. As expected, a reduction in foam density was observed in all the NRF samples as the amount of water increased. However, an increase in microwave power; from 600 to $1000 \mathrm{~W}$; had insignificant effects on foam density at all water loadings. The addition of 1.5 and $2.0 \mathrm{phr}$ water produced NRF samples with a density of less than $0.1 \mathrm{~g} / \mathrm{cm}^{3}$ for the SMC2A and SMC1A samples, respectively. These results showed a significant reduction in density than previous studies. Samsudin et al. [27] reported that the relative density of NRF produced via the heat transfer method decreased as the sodium bicarbonate content, the blowing agent, increased. The relative density of 0.356 obtained at $4 \mathrm{phr}$ sodium bicarbonate was found to decrease to 0.220 when the sodium bicarbonate content was increased to $16 \mathrm{phr}$ [27]. Najib et al. [28] obtained relative densities ranging between 0.240 to 0.257 at 4 to $12 \mathrm{phr}$ sodium bicarbonate. However, when Charoeythornkhajhornchai et al. [10] explored the effects of different types of accelerators on the density of NRF blown with azodicarbonamide (ADC), the lowest density obtained was $0.671 \mathrm{~g} / \mathrm{cm}^{3}$. Therefore, this study could be the first to produce NRF samples with densities below $0.1 \mathrm{~g} / \mathrm{cm}^{3}$, a similar range to established elastomeric polyurethane foams [29-32].

With respect to the effects of blowing agent content, the outcomes of this study corroborated the outcomes of previous studies, whereby blowing agent content significantly affected relative density [24, 27]. These studies reported that the amount of gas produced by ADC increased as the blowing agent content increased. This, consequently, increases the volume of gas in the rubber matrix and reduces foam density. Conversely, different outcomes were observed when sodium bicarbonate was utilized as the blowing agent.; i.e., when the blowing agent content was high, cell sizes were smaller and more homogeneous than low blowing agent content, which resulted in low density [28]. However, this present study obtained a peculiar foam structure. Relatively low volumes of gas were produced at low water contents, which allowed curing and foaming to occur simultaneously. This produced a high-density NRF sample with a homogeneous cell structure comprising a higher number of smaller cells. Meanwhile, NR compounds with high water contents generated high volumes of gas, leading to more rapid cell growth than the curing process. This produced large cells and increased the potential of cell coalescence that produced merged cells. Therefore, the final structure of the NRF sample was more heterogeneous and consisted of highly interconnected cells. This finding is consistent with the cell structure and cell size distribution illustrated in Figures 7-10.

\subsection{Expansion ratio}

Figure 6 depicts the expansion ratio of NRF samples with varying water loadings and different parameters. As seen, the expansion ratio increased congruently with water loading. Both sequential heating methods produced comparable results for all water loadings. A comparison of the density and expansion

Table 4. The densities and relative densities of NRF samples produced via SMC heating at different water loadings.

\begin{tabular}{|c|c|c|c|c|c|}
\hline \multirow[t]{2}{*}{ Processing method } & \multirow[t]{2}{*}{ Properties } & \multicolumn{4}{|c|}{$\begin{array}{c}\text { Water loading } \\
\text { [phr] }\end{array}$} \\
\hline & & $0.5 \mathrm{~W}$ & $1.0 \mathrm{~W}$ & $1.5 \mathrm{~W}$ & $2.0 \mathrm{~W}$ \\
\hline \multirow{2}{*}{$\begin{array}{l}\text { SMC1A: } \\
\text { MW1000_10:CH150_10 }\end{array}$} & Relative density & $0.161 \pm 0.010$ & $0.134 \pm 0.04$ & $0.115 \pm 0.004$ & $0.088 \pm 0.011$ \\
\hline & Foam density & $0.151 \pm 0.010$ & $0.125 \pm 0.004$ & $0.108 \pm 0.004$ & $0.083 \pm 0.011$ \\
\hline \multirow{2}{*}{$\begin{array}{l}\text { SMC2A: } \\
\text { :MW600_12:CH150_8 }\end{array}$} & Relative density & $0.163 \pm 0.009$ & $0.110 \pm 0.004$ & $0.097 \pm 0.005$ & $0.089 \pm 0.004$ \\
\hline & Foam density & $0.153 \pm 0.009$ & $0.103 \pm 0.004$ & $0.091 \pm 0.050$ & $0.084 \pm 0.004$ \\
\hline
\end{tabular}




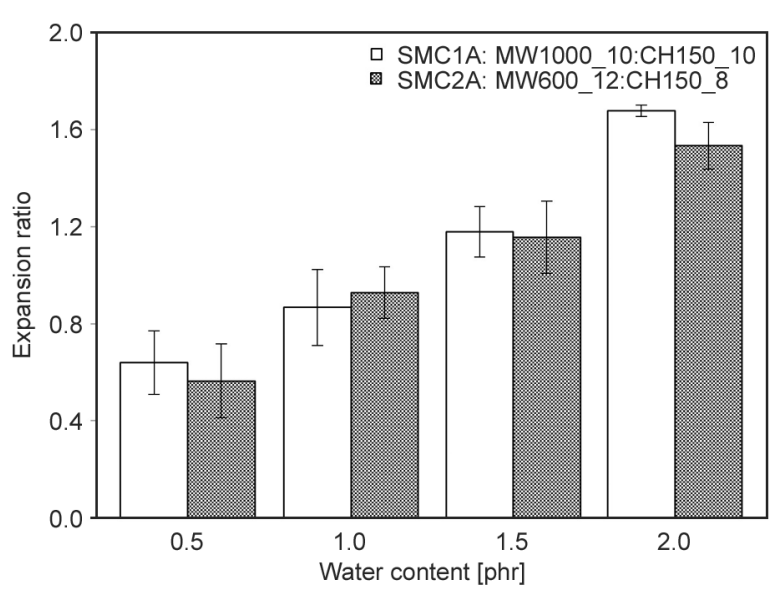

Figure 6. The effects of processing methods on the expansion ratio of NRF samples with different water loadings.

ratios indicated that although the expansion ratio increased as the water loading increased, density decreased. This implies that the expansion ratio would decrease as the density increases. It also infers that a high blowing agent content would generate a high volume of gas, thereby increasing cell size that would lead to the thinning of cell walls. Therefore, this combination ultimately modulates density and expansion ratio [24].

\subsection{Morphological studies}

Figures 7 and 8 present the microstructures of NRF samples with varying water loadings and different parameters. Images of all the NRF samples produced using different parameters showed that the NRF was composed of open-cell structures that were spherical to oval in shape. The SMC samples with low water loadings had smaller cell sizes, uniform cell size distribution, and the cells were less interconnected. Conversely, NRF samples with high water loadings had larger non-uniform cell sizes as well as more interconnected cells. Thus, the present study showed that $0.5 \mathrm{phr}$ water provides a good degree of controllability between cell growth and crosslinking due to the smaller cell size distribution and fewer interconnected cells [33]. According to Zubair et al. [34], when the low water content is used during foaming, the water may be heated slowly, thus allowing foaming and curing to occur simultaneously. Furthermore, low water content reduces the likelihood of droplet formation during foaming. Therefore, closed cells are more dominant. However, at high water contents, the presence of excess blowing agents during foaming may produce higher air pressure at the early curing stage, when crosslinks are scarce; thus, making pore boundaries coalesce, resulting in larger cell sizes with fewer pores and thin cell walls [35].

As seen in Table 5, this was corroborated as the average cell size increased as the water loading increased in the SMC1A and SMC2A samples. Additionally, both SMC heating methods produced similar average cell sizes. Furthermore, the standard deviation of NRF samples with 1.5 and $2.0 \mathrm{phr}$ water was larger than samples with 0.5 and $1.0 \mathrm{phr}$ water. This indicates that as the irregularity of the cell sizes increases, the dispersion range of the cell sizes also becomes wider. Figures 9 and 10 provide histograms of cell size distributions in the SMC1A and SMC2A samples at different water loadings that prove this. These histograms depict that the cell size distribution of NRF samples gradually broadens and shifts to a higher level. It can, therefore, be deduced that at high water loadings, the viscosity of the NR compound is reduced due to the plasticization effect of the water [33]. This allows the excessive gas generated by water decomposition to expand uncontrollably, ultimately resulting in the coalescence and rupture of the cells. Studies that investigated the effects of ADC as a blowing agent found that high amounts of ADC in the rubber matrix caused bubbles to coalesce, hence producing non-uniform cell sizes in the foam specimens [24].

In terms of foam rise direction, higher water loadings showed that cells elongated perpendicular to foam rise direction ( $y$-axis) due to free foaming (open mould) (Figure 5b) whereas foaming parallel to the foam rise direction was restricted by the dimension of the mould. Moreover, the cell walls shared by neighbouring cells became thinner until cell breakage occurred (indicated by black circles). Additionally, the open-cell structures at high water loadings comprised of two or more interconnected cells from either broken or punctured cells and missing cell walls. This was verified by the density and expansion ratio results shown in Table 4 and Figure 6, respectively.

\section{Correlation between cell structure and vulcanization characteristics}

During cell formation, competition occurs between two phenomena: foaming and vulcanization. The former depends on the volume and rate of thermal decomposition of the blowing agent, which leads to foaming progress, while the latter increases the 

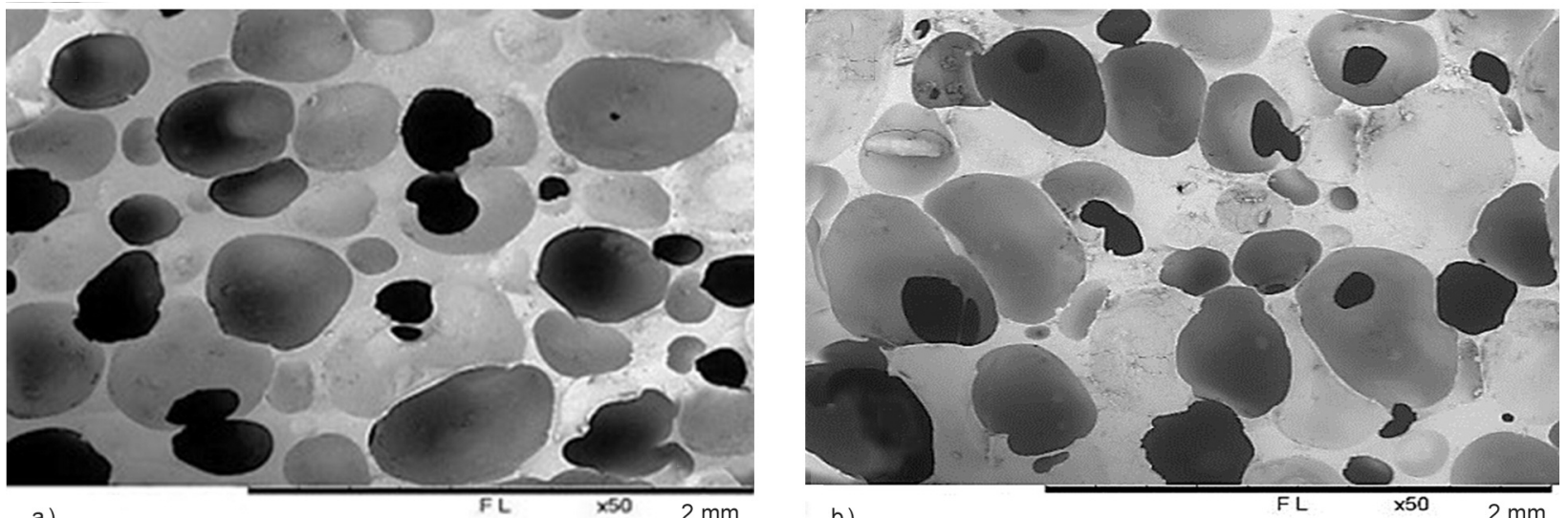

a)
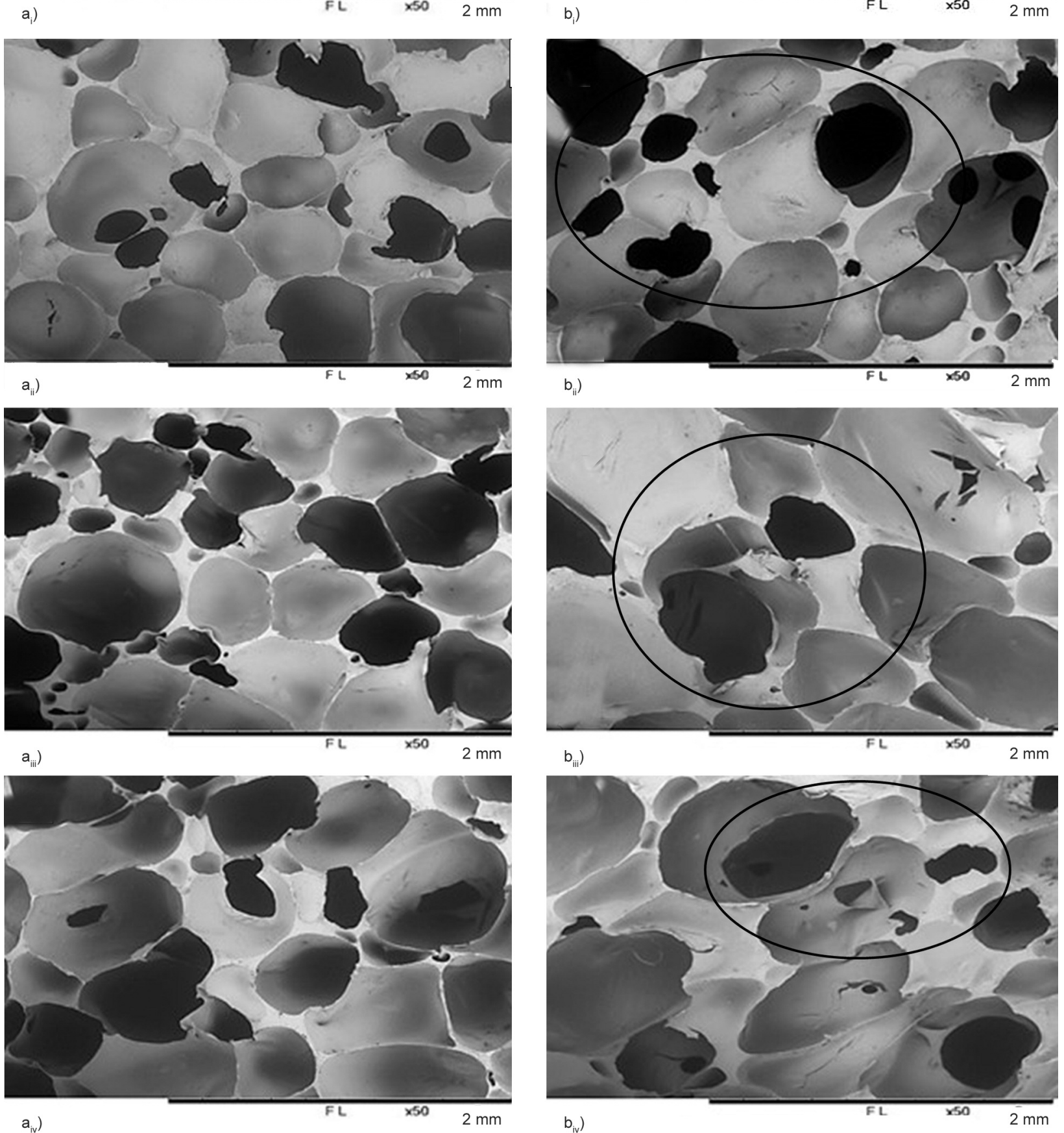

Figure 7. The morphology of the SMC1A sample (a) parallel and (b) perpendicular to foam rise direction at different water loadings. (i) $0.5 \mathrm{~W}$, (ii) $1.0 \mathrm{~W}$, (iii) $1.5 \mathrm{~W}$, (iv) $2.0 \mathrm{~W}$. 

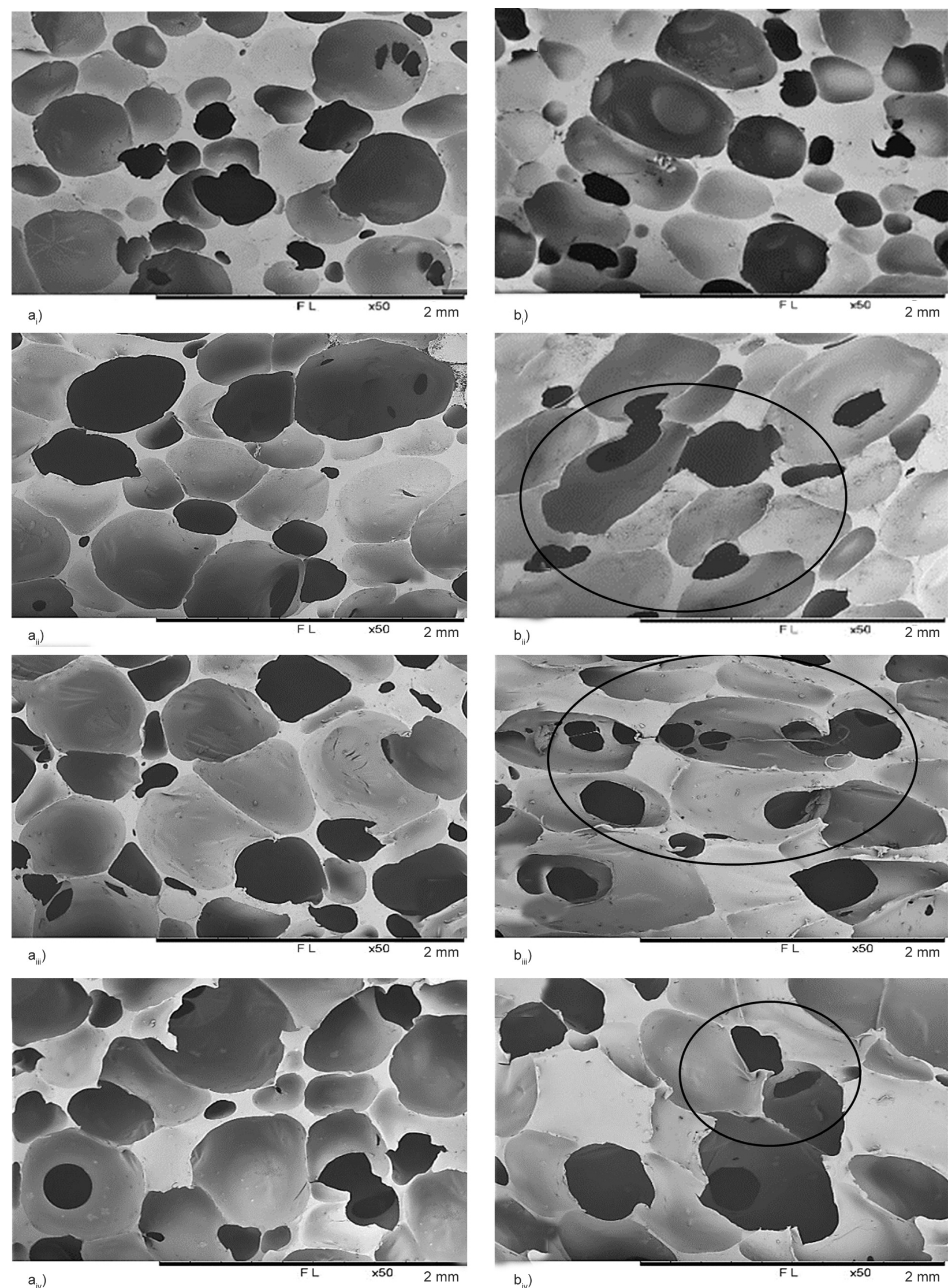

Figure 8. The morphology of the SMC2A sample (a) parallel and (b) perpendicular to foam rise direction at different water loadings. (i) $0.5 \mathrm{~W}$, (ii) $1.0 \mathrm{~W}$, (iii) $1.5 \mathrm{~W}$, (iv) $2.0 \mathrm{~W}$. 
viscosity of the matrices via crosslinking, which subsequently limits the expansion of cell growth that stabilizes the foam cell [1]. Therefore, cell size and cell structure are affected by water loading and the vulcanization reaction in the NR compound. Table 5 shows the effects of water loading on the vulcanization behaviour of NR compounds. The scorch time $\left(t_{\mathrm{s} 2}\right), 90 \%$ of cure time $\left(t_{90}\right)$, maximum torque $\left(M_{\mathrm{H}}\right)$, and minimum torque $\left(M_{\mathrm{L}}\right)$ decreased as the water content increased, indicating that the addition of water to the rubber matrix decreased the viscosity of the NR compound. Therefore, a shorter time period was required to initiate the vulcanization process in NRF samples. Furthermore, NRF samples with low water contents had the longest scorch times and the highest torque because less gas was produced during water decomposition than NRF samples with higher water loadings. Charoeythornkhajhornchai et al. [10] had similar findings as the gas produced during the decomposition of the blowing agent in the rubber system reduced torque due to an increase in the crosslink reaction of the rubber compared to rubber compounds without a blowing agent. As water content was found to affect the curing behaviour of NR compounds, it probably reacts with one or more of the curing components in the rubber system. The scorch time decreased as water loading increased due to the hydrolysis of the benzothiazole sulfenamide accelerator at the nitrogen-sulphur bond, forming other chemicals [10]. This, in turn, decreased its concentration and delayed the onset of the crosslinking reaction to a shorter period. As a similar type of accelerator was used in this present study, it is believed that the addition of water might accelerate the crosslink reaction as the water loading increases leading to increased hydrolysis. Minimum torque $\left(M_{\mathrm{L}}\right)$ measures the stiffness of unvulcanized rubber compounds and is taken at the lowest point of the cure curve $[1,36]$. The results showed that $M_{\mathrm{L}}$ decreased as water loading increased. This can be elucidated by a decrease in viscosity as the water content increased due to plastic deformation and the ability of water to increase the chain mobility of rubber. This shows that, at high water contents, the plasticization effect increases the ability of cell expansion and combination, creating larger cell sizes. Maximum torque $\left(M_{\mathrm{H}}\right)$ determines the stiffness or shear modulus of vulcanized rubber compounds at the vulcanization temperature [36]. A reduction in $M_{\mathrm{H}}$ with water loadings is expected due to the higher amount of gas produced during the decomposition of water. A similar outcome was also obtained from the difference between the maximum and minimum torque $(\Delta S)$, indicating that the crosslinking density of the NRF samples decreased as the water content increased. A study by Pechurai et al. [3] attributed the decreasing of $M_{\mathrm{H}}$ as BA increased to the generation of high amounts of nitrogen gas in the rubber system and the concurrent formation of more microvoids that reduced the shear force.

As seen in Table 5, the cure rate index $(C R I)$ increased as the water loading increased. An increment from 0.5 to $2.0 \mathrm{phr}$ water increased the $C R I$ by $12.55 \mathrm{~min}^{-1}$. CRI increases as water loading increases because water is a polar inorganic compound in nature; hence it is able to increase activating sites for vulcanization [37]. Additionally, the increment is also attributed to the high addition of water in the rubber compound, which increases the hydroxyl group and rate of vulcanization [37]. Despite that, the results seen in Figures 9 and 10 and Table 6 indicate that cell size increased as water loading increased. This suggests that the foaming rate was faster than the vulcanization rate. Water turns into a vapour at $100^{\circ} \mathrm{C}$, while vulcanization normally occurs at 150 to $170^{\circ} \mathrm{C}$. Therefore, the high amount of gas generated at higher water loadings promotes cell expansion leading to the combination of two or more cells and cell coalescence, larger cell sizes, and nonuniform cell sizes (Figures 9, 10 and Table 6).

Table 5. The curing characteristics of water loaded NR compounds.

\begin{tabular}{|c|c|c|c|c|c|c|}
\hline $\begin{array}{c}\text { Water content } \\
{[\mathbf{p h r}]}\end{array}$ & $\begin{array}{c}\boldsymbol{t}_{\mathbf{s} 2} \\
{[\mathbf{m i n}]}\end{array}$ & $\begin{array}{c}\boldsymbol{t}_{\mathbf{9 0}} \\
{[\mathbf{m i n}]}\end{array}$ & $\begin{array}{c}\boldsymbol{M}_{\mathbf{H}} \\
{[\mathbf{d N} \cdot \mathbf{m}]}\end{array}$ & $\begin{array}{c}\boldsymbol{M}_{\mathbf{L}} \\
{[\mathbf{d N} \cdot \mathbf{m}]}\end{array}$ & $\begin{array}{c}\Delta \boldsymbol{S}^{*} \\
{[\mathbf{d N} \cdot \mathbf{m}]}\end{array}$ & $\begin{array}{c}\boldsymbol{C R I} \\
{\left[\mathbf{m i n}^{-1}\right]}\end{array}$ \\
\hline 0.5 & 3.60 & 6.27 & 5.17 & 0.06 & 5.11 & 37.45 \\
\hline 1.0 & 3.33 & 5.67 & 4.91 & 0.05 & 4.86 & 42.74 \\
\hline 1.5 & 3.15 & 5.47 & 4.83 & 0.05 & 4.78 & 43.10 \\
\hline 2.0 & 2.97 & 4.97 & 4.61 & 0.01 & 4.60 & 50.00 \\
\hline
\end{tabular}

${ }^{*} \Delta S=\left(M_{\mathrm{H}}-M_{\mathrm{L}}\right)$ 

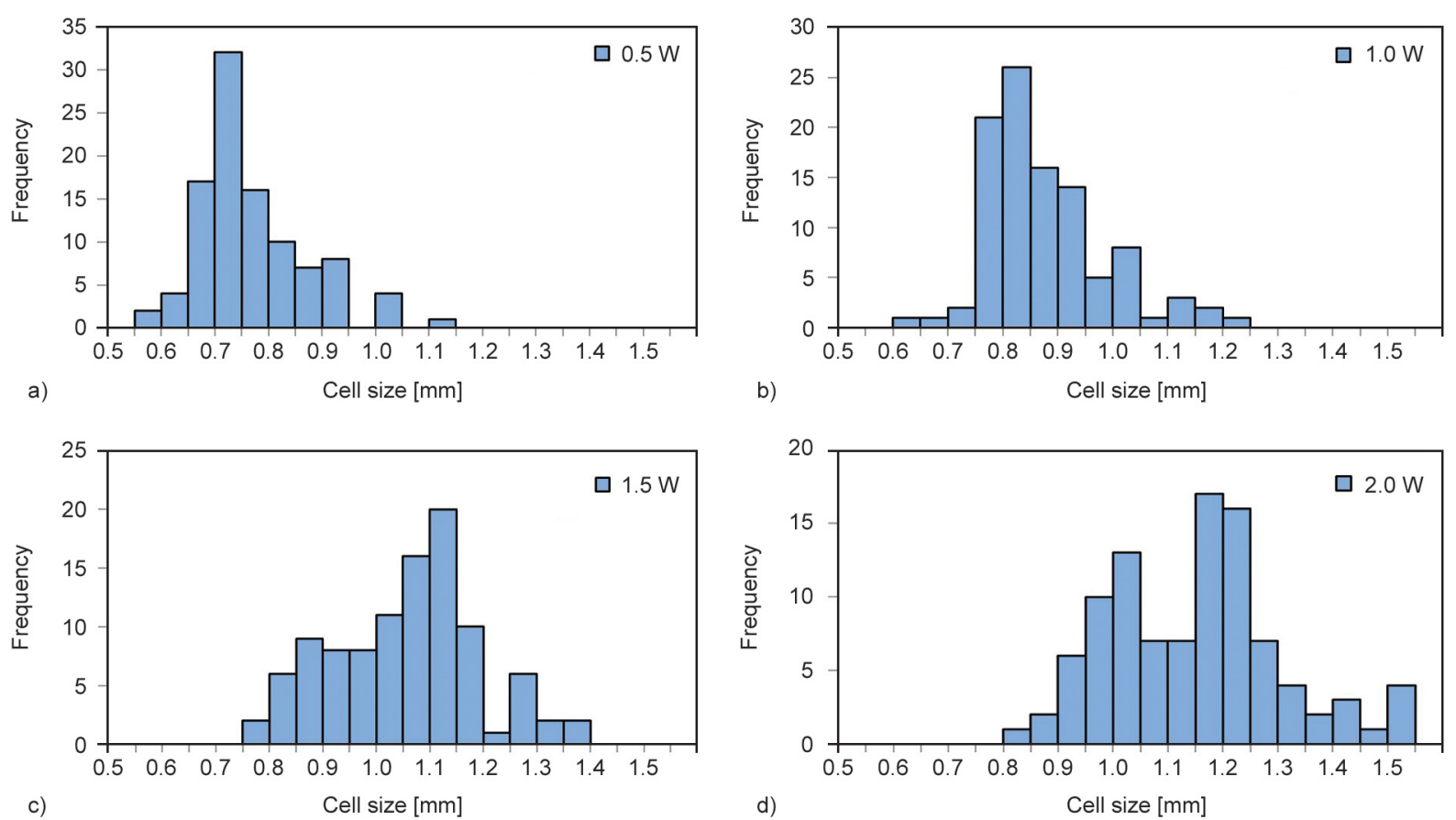

Figure 9. The cell size distribution observed in the cross-section parallel to foam rise direction of the SMC1A sample at (a) $0.5 \mathrm{phr}$, (b) $1.0 \mathrm{phr}$, (c) $1.5 \mathrm{phr}$, and (d) $2.0 \mathrm{phr}$ water.
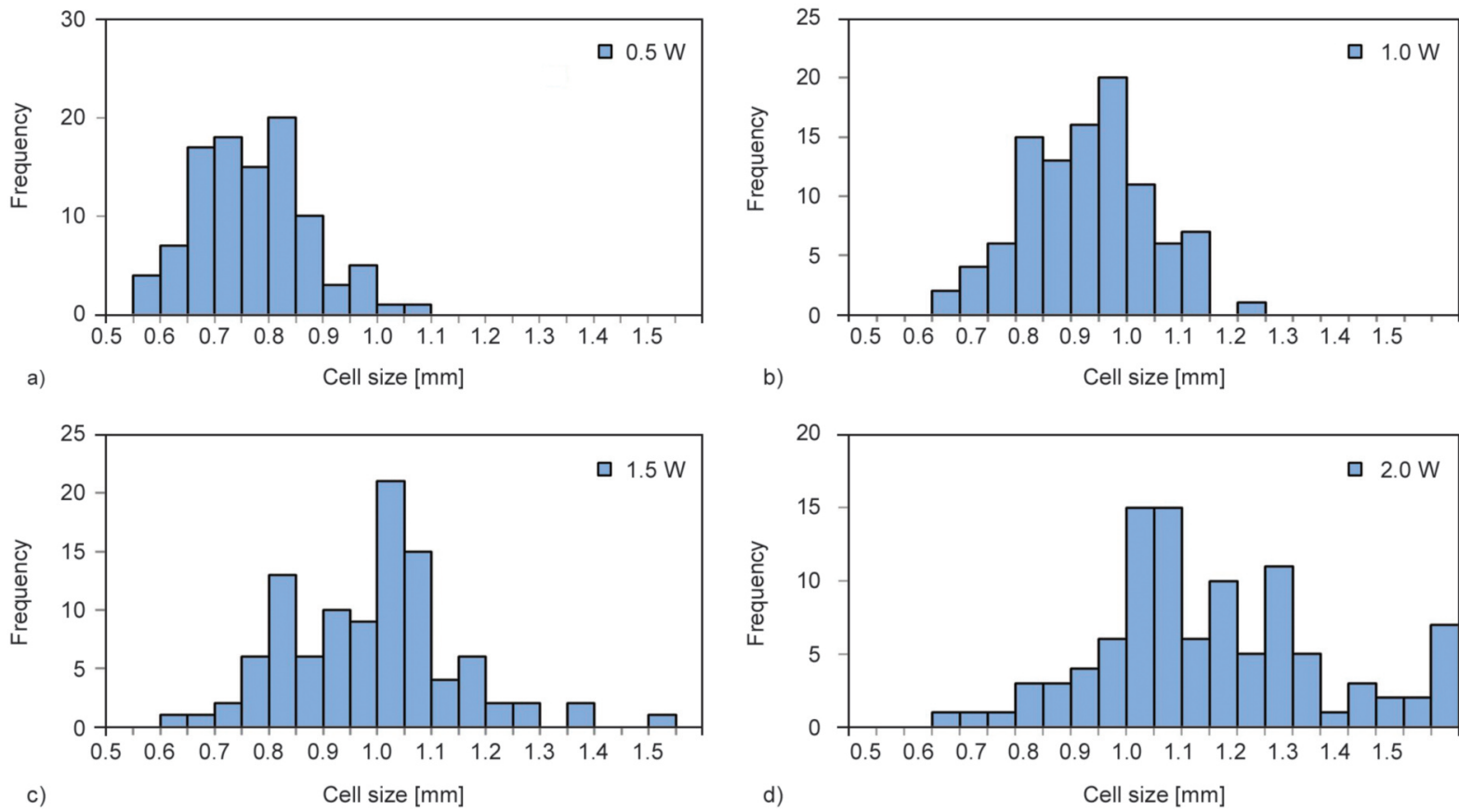

Figure 10. The cell size distribution observed in the cross-section parallel to foam rise direction of the SMC2A sample at (a) $0.5 \mathrm{phr}$, (b) $1.0 \mathrm{phr}$, (c) $1.5 \mathrm{phr}$, and (d) $2.0 \mathrm{phr}$ water.

\subsection{Cell size and density}

Table 6 shows the average cell size and cell density of NRF samples with different water loadings produced using two different heating techniques. A comparison of the SMC1A and SMC2A samples showed that both heating techniques had similar trends and the data in the same range. The results revealed that average cell size increased and cell density decreased as the water loading increased during both heating techniques. This was expected as more gas is generated as the water loading increases and the combination of cells becomes more prominent rather than creating new cells, subsequently leading to the growth of large irregular cells. Hemmasi et al. [38] 
Table 6. The cell size and density of NRF samples with varying water loadings subjected to different heating techniques.

\begin{tabular}{|c|c|c|c|}
\hline \multirow{2}{*}{ Heating technique } & $\begin{array}{c}\text { Water loading } \\
{[\mathbf{p h r}]}\end{array}$ & $\begin{array}{c}\text { Average cell size } \\
{[\mathbf{m m}]}\end{array}$ & $\begin{array}{c}\text { Cell density } \\
{\left[\mathbf{c m}^{-3}\right]}\end{array}$ \\
\hline \multirow{3}{*}{ SMC1A } & 0.5 & $0.072 \pm 0.010$ & $842.748 \pm 293.992$ \\
\cline { 2 - 4 } & 1.0 & $0.083 \pm 0.013$ & $537.056 \pm 216.210$ \\
\cline { 2 - 4 } & 1.5 & $0.100 \pm 0.016$ & $299.048 \pm 133.658$ \\
\hline \multirow{3}{*}{ SMC2A } & 2.0 & $0.107 \pm 0.027$ & $276.731 \pm 201.614$ \\
\cline { 2 - 4 } & 0.5 & $0.072 \pm 0.011$ & $876.089 \pm 299.527$ \\
\cline { 2 - 4 } & 1.0 & $0.089 \pm 0.015$ & $424.461 \pm 212.527$ \\
\cline { 2 - 4 } & 1.5 & $0.092 \pm 0.014$ & $364.534 \pm 173.814$ \\
\hline
\end{tabular}

reported that when cells nucleated, they continued to expand and diffuse into the other nucleated cells. In terms of cell density, low cell density may be due to a decrease in cell wall thickness due to increased cell size. It depends on the cell growth mechanism, i.e., the amount of gas that was dissolved in the rubber matrix during the foaming process. Another interesting point is that the cell density decreased as the water loading increased in both heating techniques due to the plasticization effect of water as it promotes cell growth and produces thin cell walls, as indicated by arrows in Figures 7 and 8 .

\subsection{Potential heating mechanisms}

In this subsection, the potential heating mechanisms of single heating methods, $\mathrm{MH}$ and $\mathrm{CH}$ (Figure 11), and sequential heating methods, SMC and SCM (Figure 12), are proposed and compared. The proposed heating mechanisms were based on the physical and morphological properties obtained and discussed in the previous section. The purpose of these heating mechanisms was to develop an in-depth understanding of the differences between the heating methods used, which were $\mathrm{CH}$ and $\mathrm{MH}$.

\subsubsection{Heating mechanism of single heating methods}

According to the results of the single and sequential heating methods, the heating mechanisms of each method greatly differ. The potential heating mechanism of each heating method proposed and illustrated in Figures 11 and 12 are based on observations and analyses of the NRF samples. During $\mathrm{CH}$, heat that is generated by the heating source travels to the surface of the sample via radiation, conduction, and convection. As seen in Figure 11 $\mathrm{a}_{\mathrm{i}}$, the heating source during $\mathrm{CH}$ in this study was located at the top of the oven chamber. Therefore, the skin layer of the samples received the highest amount of energy than the inner parts and crosslinking began immediately before the heat was transferred into the sample (Figure $11 \mathrm{a}_{\mathrm{ii}}$ ). However, the glass mould could have accelerated the curing process on all sides of the sample because the glass could have conducted and transferred heat faster to the surface of samples that are in contact with the walls of the mould. The crosslinked parts at the top and sides of the sample could entrap the emitted gas within the sample, which was then displaced as one unit, thus causing the sample to have a convex shape and a smooth blister-free surface. As seen in Figure $3 \mathrm{c}$, the cross-sections of NRF samples produced via $\mathrm{CH}$ revealed that $\mathrm{CH}$ produces uneven cells due to cell coalescence. This was because the foaming process was faster than the crosslinking reaction; thus the gas produced in the rubber system had ample time to expand and diffuse in the rubber matrix, resulting in the emergence of cells. This incident can be further explained by considering that the heat gradually travelled from the hottest area (the sample's surface) to the coldest area (inside the sample) due to a temperature gradient before reaching the bottom surface through heat conduction [26]. This phenomenon may cause significant temperature differences inside the sample, creating an imbalance between the foaming and curing processes that ultimately create wide-ranging cell sizes.

In $\mathrm{MH}$, a waveguide produces electromagnetic (EM) waves that penetrate the NR compound and excite the water and dipole components evenly throughout the sample thickness. Therefore, MH provides uniform, rapid, and volumetric heating as all the molecules are excited concurrently rather than conducting heat $[39,40]$. The curing mechanism of MH in NR compounds occurs when the sample absorbs EM waves, generating an electric field inside the compound. This electric field can initiate changes in rotation, 
Convection heating $(\mathrm{CH})$

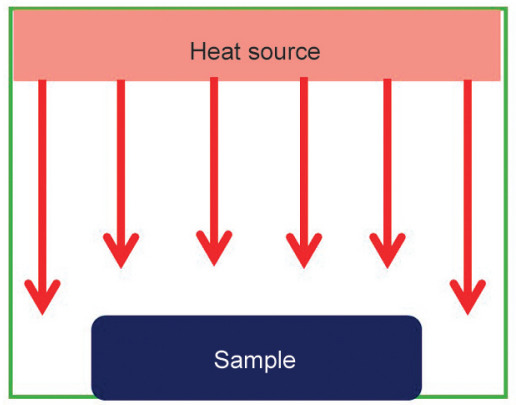

$\left.a_{i}\right)$ Heat is transferred from the heat source to the sample

Microwave heating $(\mathrm{MH})$

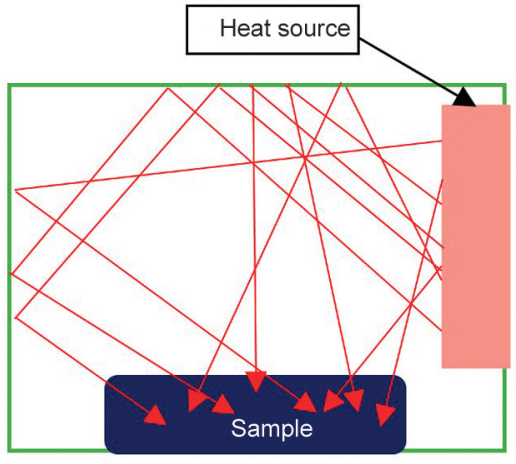

$\left.b_{i}\right)$ EM waves penetrates the sample thickmess

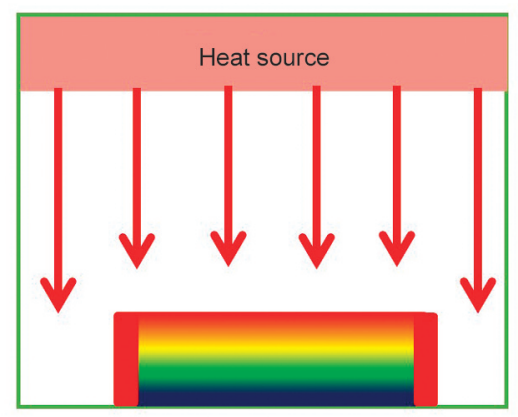

$\left.a_{i i}\right)$ The top and side surface of the sample receive the highest heat

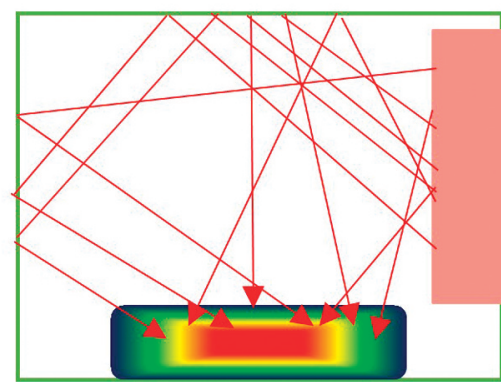

$\left.b_{i i}\right)$ Heat is generated inside the sample

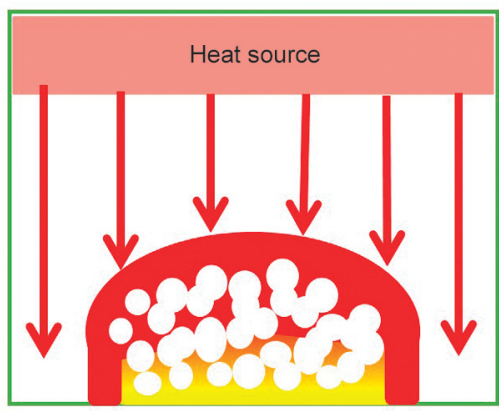

$a_{\text {iii }}$ ) As heat travels through the sample thickness, foaming and curing are initiated

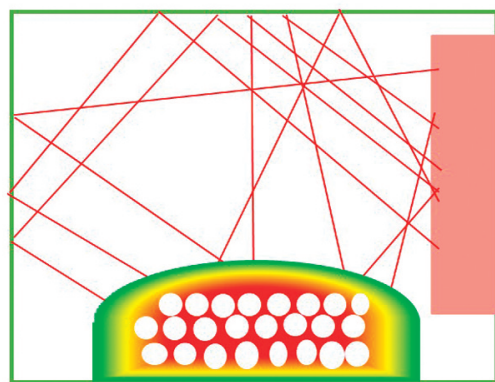

$b_{\mathrm{iii}}$ ) Foaming and curing occur inside the sample and travels to the outside

Temperature indicator

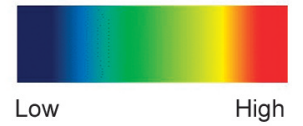

Figure 11. The potential heating mechanisms of single heating methods: (a) convection heating and (b) microwave heating.

vibration, and polarisation of the rubber molecules [40]. As such, dipole molecules rotate rapidly and produce friction that generates heat. This causes the temperature to rise within the rubber compound, thereby initiating the curing process. Meanwhile, ionic compounds in the NR compound are accelerated by EM waves causing them to collide with other molecules and disrupt the hydrogen bond with water, thus generating additional heat $[19,33]$. An NR is a non-polar material that has relatively transparent properties for MH [41]. Therefore, as water is a good microwave absorber, its addition provides good heat distribution and accelerates the heating of NR compounds.

Figure $11 \mathrm{~b}$ illustrates the potential heating mechanism of MH. As seen in Figures $11 b_{i}$ and $11 b_{i i}$, heat radiates from within the sample to the outer layer (volumetric heating). The temperature is at its highest within the sample, as indicated by its red colour, while the outer layer registers the lowest temperature (blue colour). As such, as foaming and crosslinking are initiated from the middle of the sample, the sample has a flat surface (Figure $11 b_{\text {iii) }}$. Furthermore, MH produced NRF samples with uneven skin and several blisters breaching the skin. This indicates that, due to the lower temperature of the microwave chamber, crosslinking is delayed at the surface of the sample as it is not heated directly by microwave radiation (Figure $11 b_{\text {iii }}$ ). According to Chavan and Chavan [20], the main difference between $\mathrm{MH}$ and $\mathrm{CH}$ is that the temperature of the microwave chamber is maintained at ambient temperature, causing the surface of the sample to register low temperatures. Moreover, due to the high rate of internal heating, moisture evaporation also occurs and develops a pressure-driven flow. Therefore, moisture is transported from the inner part of the sample to the surface, where it accumulates before eventually evaporating and forming blisters [12, 39]. 


\subsubsection{Heating mechanism of sequential heating methods}

Figure 12 illustrates the potential heating mechanisms of SCM and SMC heating. MH was adopted as the first heating method due to the benefits of volumetric heating, which produces even cell sizes (Figure 12a). The heating source was then switched to $\mathrm{CH}$ to cure the outer layer of the sample (Figure $12 \mathrm{a}_{\mathrm{iii}}$ ). In the case of SCM heating (Figure 12b), $\mathrm{CH}$ was utilized as the first heating method to cure the outer layer. However, as $\mathrm{CH}$ relies on heat transfer, foaming and curing may occur at different stages. When $\mathrm{CH}$ was halted, and the heating source switched to MH (Figure $12 b_{\text {iii }}$ ), certain layers may register higher temperatures than others. This causes inhomogeneous heat distribution that produces non-uniform cell sizes.

\section{Conclusions}

Natural rubber (NR) compounds of varying water loadings were prepared to examine the efficacy of single heating and sequential heating using microwave and convection heating at different parameter settings. The effects of water loading, microwave power, temperature of convection heating, and exposure time were investigated by evaluating the physical and morphological properties of the final natural rubber foam (NRF) samples. Optimum parameters were obtained using sequential heating using microwave heating followed by convection heating (SMC). The other heating methods produced irregular and uncontrollable foaming. The crosslink density, density, cell size, and expansion ratio of the SMC2A (600_12:150_8) sample were comparable with that of the SMC1A (1000_10:150_10) sample.

Sequential microwave convention (SMC)

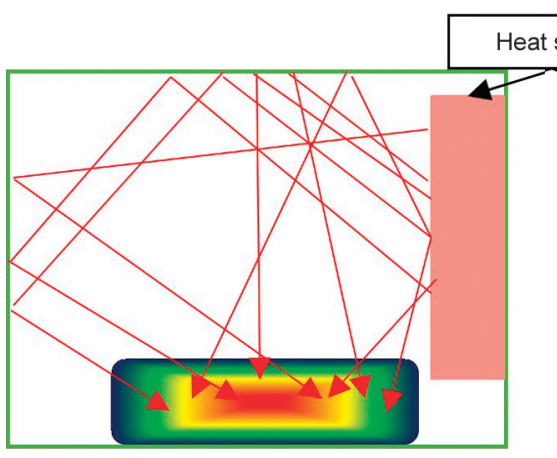

$\mathrm{a}_{\mathrm{i}}$ ) EM waves penetrate the sample thickness to generate and transfer heat from inside the sample to the outside

Sequential convection microwave (SCM)

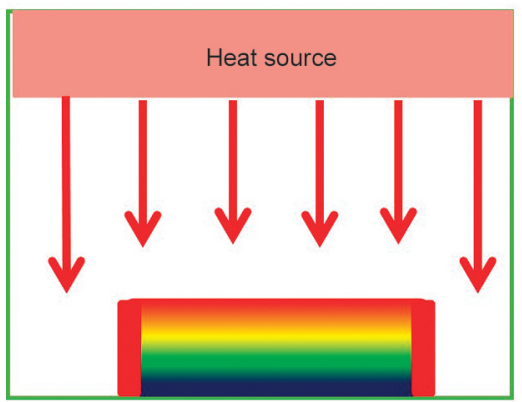

$\left.b_{i}\right)$ Heat is transferred from the heat source to the outer layer of the sample and travels throughout the sample thickness is stages

Temperature indicator

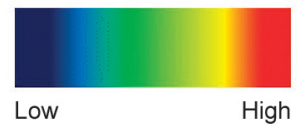

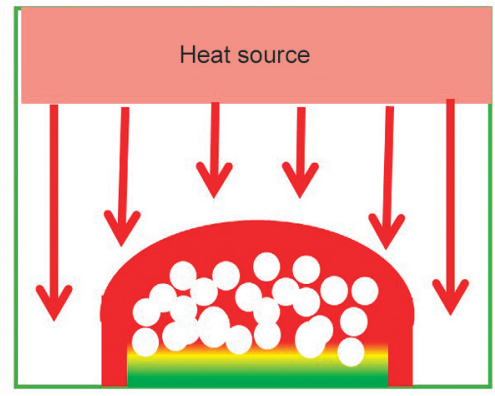

$\mathrm{b}_{\mathrm{ii}}$ ) As the outer layer is cured first, foaming and curing occur inside the sample in stages

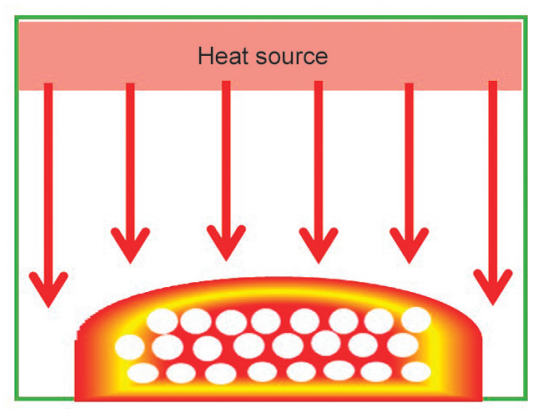

$\left.a_{i i i}\right)$ The outer layer is heated using $\mathrm{CH}$ to cure and prevent blisters from forming ii sample and is transferred to the outsid sample and is transferred to the outsid
before the heating source is switched to $\mathrm{CH}$

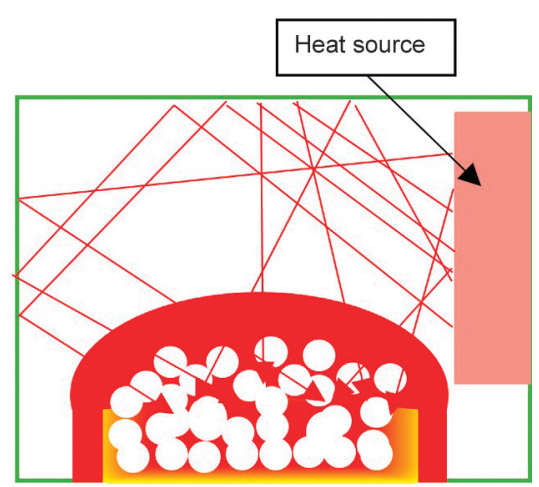

$\mathrm{b}_{\mathrm{iii}}$ ) MH then accelerates the heating process inside the sample

Figure 12. The potential mechanisms of sequential heating methods: (a) SMC heating and (b) SCM heating. 
However, the SMC2A sample had ideal parameter settings because the heating was conducted at low microwave power. In terms of water loading, the SMC1A sample had the lowest relative density $(0.088)$ at a water loading of $2.0 \mathrm{phr}$. Further investigation revealed that the NRF sample with $2.0 \mathrm{phr}$ water had the highest expansion ratio, bigger cell sizes, more irregular cell sizes, and a high number of interconnected cells than NRF samples with other water loadings. A high number of interconnected cells and a low density are good indicators of foams that are suitable for use as acoustic absorbing materials and thermal insulators. However, the correlation between cell size and cell structure for use in specific applications warrants further investigation. In conclusion, water could potentially replace chemical blowing agents in the production of NRF products, thereby promoting innovation towards green and sustainable materials. Additionally, as microwaveassisted foaming produces NRF products with open cell structures, it could be a good candidate with which to reduce reliance on synthetic foams in acoustic and thermal insulation applications.

\section{Acknowledgements}

The authors would like to thank Universiti Sains Malaysia for the financial support provided through the Research University (RUI) grant (Ref. No.: 1001/PBAHAN/8014041) and Universiti Malaysia Sarawak.

\section{References}

[1] Rostami-Tapeh-Esmaiel T., Vahidifar A., Esmizadeh E., Rodrigue D.: Chemistry, processing, properties, and applications of rubber foams. Polymers, 13, 1565-1615 (2021). https://doi.org/10.3390/polym13101565

[2] Prasopdee T., Smitthipong W.: Effect of fillers on the recovery of rubber foam: From theory to applications. Polymers, 12, 2745-2752 (2020). https://doi.org/10.3390/polym12112745

[3] Pechurai W., Muansupan T., Seawlee P.: Effect of foaming temperature and blowing agent content on cure characteristics, mechanical and morphological properties of natural rubber foams. Advanced Materials Research, 844, 454-457 (2014).

https://doi.org/10.4028/www.scientific.net/amr.844.454

[4] Stehr J.: Chemical blowing agents in the rubber industry. Past - present - and future? International Polymer Science and Technology, 43, 1-10 (2016). https://doi.org/10.1177/0307174X1604300501
[5] Ariff Z. M., Zakaria Z., Tay L. H., Lee S. Y.: Effect of foaming temperature and rubber grades on properties of natural rubber foams. Journal of Applied Polymer Science, 107, 2531-2538 (2008).

https://doi.org/10.1002/app.27375

[6] Ku H. S., Siores E., Ball J. A. R.: Review - Microwave processing of materials: Part I. HKIE Transactions, 8 , 31-37 (2001). https://doi.org/10.1080/1023697X.2001.10667855

[7] Demitri C., Giuri A., Raucci M. G., Giugliano D., Madaghiele M., Sannino A., Ambrosio L., Demitri C.: Preparation and characterization of cellulose-based foams via microwave curing. Interface Focus, 4, 20130053 (2014).

https://doi.org/10.1098/rsfs.2013.0053

[8] Zhang F., Zhou T., Liu Y., Leng J.: Microwave synthesis and actuation of shape memory polycaprolactone foams with high speed. Scientific Reports, 5, 11152 (2015). https://doi.org/10.1038/srep11152

[9] Prociak A., Michałowski S., Bąk S.: Thermoplastic polyurethane foamed under microwave irradiation. Polimery, 57, 786-790 (2012). https://doi.org/10.14314/polimery.2012.786

[10] Charoeythornkhajhornchai P., Samthong C., Somwangthanaroj A.: Influence of sulfenamide accelerators on cure kinetics and properties of natural rubber foam. Journal of Applied Polymer Science, 134, 44822 (2017).

https://doi.org/10.1002/app.44822

[11] Sahnoune A.: Foaming of thermoplastic elastomers with water. Journal of Cellular Plastics, 37, 149-159 (2001). https://doi.org/10.1106/E7WD-X288-XFK7-6E90

[12] Hopmann C., Lemke F., Binh Q. N.: Foaming of EPDM with water as blowing agent in injection molding. Journal of Applied Polymer Science, 133, 43613 (2016). https://doi.org/10.1002/app.43613

[13] Lee E-K., Choi S-Y.: Preparation and characterization of natural rubber foams: Effects of foaming temperature and carbon black content. Korean Journal of Chemical Engineering, 24, 1070-1075 (2007).

https://doi.org/10.1007/s11814-007-0123-6

[14] Kim J-H., Choi K-Y., Yoon J-M.: The foaming characteristics and physical properties of natural rubber foams: Effects of carbon black content and foaming pressure. Journal of Industrial and Engineering Chemistry, 12, 795-801 (2006).

[15] Zakaria Z., Ariff Z. M., Hwa T. L., Sipaut C. S.: Effect of foaming temperature on morphology and compressive properties of ethylene propylene diena monomer rubber (EPDM) foam. Malaysian Polymer Journal, 2, 22-30 (2007).

[16] Kim D. Y., Park J. W., Lee D. Y., Seo K. H.: Correlation between the crosslink characteristics and mechanical properties of natural rubber compound via accelerators and reinforcement. Polymers, 12, 2020 (2020). https://doi.org/10.3390/polym12092020 
[17] Mahamood M. A., Mohamad N., Jeeffeerie A. R., Zain A. H. M., Shueb M. I., Effendy A. M. H.: Physical properties and energy absorption characteristic of open cell ENR /RR foam. in 'Proceeding of Malaysian International Tribology Conference. Penang, Malaysia' 62-63 (2015).

[18] Zauzi N. S. A., Ariff Z. M., Khimi S. R.: Foamability of natural rubber via microwave assisted foaming with azodicarbonamide (ADC) as blowing agent. Materials Today: Proceeding, 17, 1001-1007 (2019). https://doi.org/10.1016/j.matpr.2019.06.498

[19] Bhattacharya M., Basak T.: A review on the susceptor assisted microwave processing of materials. Energy, 97, 306-338 (2016). https://doi.org/10.1016/j.energy.2015.11.034

[20] Chavan R. S., Chavan S. R.: Microwave baking in food industry: A review. International Journal of Dairy Science, 5, 113-127 (2010). https://doi.org/10.3923/ijds.2010.113.127

[21] Kumnuantip C., Sombatsompop N.: Effect of reclaimed rubber content in NR/carbon black vulcanizates using microwave irradiation system. in 'ANTEC 2005, Annulal Conference of the Society of Plastic Engineers. Boston, USA, Vol. 10, 3048-3052 (2005).

[22] Vieira M. G. A., da Silva M. A., dos Santos L. O., Beppu M. M.: Natural-based plasticizers and biopolymer films: A review. European Polymer Journal, 47, 254-263 (2011).

https://doi.org/10.1016/j.eurpolymj.2010.12.011

[23] Zhu Z., Guo W.: Frequency, moisture content, and temperature dependent dielectric properties of potato starch related to drying with radio-frequency/microwave energy. Scientific Reports, 7, 9311 (2017). https://doi.org/10.1038/s41598-017-09197-y

[24] Charoeythornkhajhornchai P., Samthong C., Boonkerd K., Somwangthanaroj A.: Effect of azodicarbonamide on microstructure, cure kinetics and physical properties of natural rubber foam. Journal of Cellular Plastics, 53, 287-303 (2017).

https://doi.org/10.1177/0021955X16652101

[25] Anwar J., Shafique U., Waheed-uz-Zaman, Rehman R., Salman M., Dar A., Anzano J. M., Ashraf U., Ashraf S.: Microwave chemistry: Effect of ions on dielectric heating in microwave ovens. Arabian Journal of Chemistry, 8, 100-104 (2015). https://doi.org/10.1016/j.arabjc.2011.01.014

[26] Ibrahim U. K., Mohd Salleh R., Zhou W.: Radiation heat transfer analysis in high emissivity baking oven using network representation method. APCBEE Procedia, 3, 11-16 (2012).

https://doi.org/10.1016/j.apcbee.2012.06.038

[27] Samsudin M. S. F., Ariff Z. M., Ariffin A.: Deformation behavior of open-cell dry natural rubber foam: Effect of different concentration of blowing agent and compression strain rate. AIP Conference Proceedings, 1835, 020007 (2017).

https://doi.org/10.1063/1.4981829
[28] Najib N. N., Ariff Z. M., Manan N. A., Bakar A. A., Sipaut C. S.: Effect of blowing agent concentration on cell morphology and impact properties of natural rubber foam. Journal of Physical Science, 20, 13-25 (2009).

[29] Lim H., Kim E. Y., Kim B. K: Polyurethane foams blown with various types of environmentally friendly blowing agents. Plastic, Rubber and Composites, 39, 364-369 (2016). https://doi.org/10.1179/174328910X12691245469835

[30] Tao W-H., Hsu H-C., Chang C-C., Hsu C-L., Lin Y-S.: Measurement and prediction of thermal conductivity of open cell rigid polyurethane foam. Journal of Cellular Plastics, 37, 310-332 (2001).

https://doi.org/10.1106\%2F1X25-NV25-LUA2-GHR3

[31] Thirumal M., Khastgir D., Singha N. K., Manjunath B. S., Naik Y. P.: Effect of foam density on the properties of water blown rigid polyurethane foam. Journal of Applied Polymer Science, 108, 1810-1817 (2008).

https://doi.org/10.1002/app.27712

[32] Chen S., Jiang Y., Chen J., Wang D.: The effects of various additive components on the sound absorption performances of polyurethane foams. Advances in Materials Science and Engineering, 2015, 317561 (2015). https://doi.org/10.1155/2015/317561

[33] Meng L., Liu H., Yu L., Duan Q., Chen L., Liu F., Shao Z., Shi K., Lin X.: How water acting as both blowing agent and plasticizer affect on starch-based foam. Industrial Crops and Products, 134, 43-49 (2019). https://doi.org/10.1016/j.indcrop.2019.03.056

[34] Zubair M., Ferrari R., Alagha O., Mu'azu N. D., Blaisi N. I., Ateeq I. S., Manzar M. S.: Microwave foaming of materials: An emerging field. Polymers, 12, 2477 (2020).

https://doi.org/10.3390/polym12112477

[35] Fauzi M. S., Lan D. N. U., Osman H., Ghani S. A.: Effect of sodium bicarbonate as blowing agent on production of epoxy shape memory foam using aqueous processing method. Sains Malaysiana, 44, 869-874 (2015). https://doi.org/10.17576/jsm-2015-4406-13

[36] Kim J-H., Koh J-S., Choi K-C., Yoon J-M., Kim S-Y.: Effects of foaming temperature and carbon black content on the cure characteristics and mechanical properties of natural rubber foams. Journal of Industrial and Engineering Chemistry, 13, 198-205 (2007).

[37] Mohd Nor N. A., Othman N.: Effect of filler loading on curing characteristic and tensile properties of palygorskite natural rubber nanocomposites. Procedia Chemistry, 19, 351-358 (2016).

https://doi.org/10.1016/j.proche.2016.03.023

[38] Hemmasi A. M., Khademi-Eslam H., Pouraabbasi S., Ghasemi I., Talaiepour M.: Cell morphology and physico-mechanical properties of HDPE/EVA/rice hull hybrid foamed composites. BioResources, 6, 2291-2308 (2011). 
[39] Chen H-L., Li T., Xing K., Li K-L., Zhang M-D., Li QL.: Experimental investigation of technological conditions and temperature distribution in rubber material during microwave vulcanization process. Journal of Thermal Analysis and Calorimmetry, 130, 2079-2091 (2017).

https://doi.org/10.1007/s10973-017-6601-0

[40] Datta A. K., Rakesh V.: Principles of microwave combination heating. Comprehensive Reviews in Food Science and Food Safety, 12, 24-39 (2013).

https://doi.org/10.1111/j.1541-4337.2012.00211.x
[41] Formela K., Hejna A., Zedler Ł., Colom X., Cañavate J.: Microwave treatment in waste rubber recycling Recent advances and limitations. Express Polymer Letters, 13, 565-588 (2019).

https://doi.org/10.3144/expresspolymlett.2019.48 